\title{
Arqueología histórica en la plazuela de San Francisco y el hallazgo de la primera Iglesia de Nuestra Señora de la Soledad
}

\section{Historical archeology in the Plazuela de San Francisco and the discovery of the first Church of Nuestra Señora de la Soledad}

\author{
Harry Pizarro Anaya \\ https://orcid.org/oooo-0002-4434-9584 \\ Universidad Nacional Mayor de San Marcos \\ harry.pizarro@unmsm.edu.pe
}

\section{RESUMEN}

El Plan Maestro del Centro Histórico de Lima (CHL) incluye la recuperación de sus espacios públicos. En ese contexto se están ejecutando diversos proyectos de arqueología histórica en algunas de sus plazuelas más importantes.

El objetivo principal fue identificar los distintos procesos de renovación de estos espacios, con la premisa que funcionaron como eje integrador del tejido urbano del centro de Lima como espacios sociales dinámicos desde sus tiempos fundacionales. Las plazuelas estudiadas a partir de sus palimpsestos nos permiten repensar su memoria histórica.

Desde una visión multidisciplinaria se estudió el devenir de la actual plazuela de San Francisco, desde sus orígenes en los albores del siglo XVII, hasta su configuración actual como uno de los más destacados e importantes espacios públi- 
cos del CHL. Se presentan los resultados del proyecto de arqueología histórica "Plazuelas de Lima" (2019-2020). ${ }^{1}$

Palabras clave: arqueología histórica; Lima virreinal; arquitectura religiosa.

\section{ABSTRACT}

The Master Plan of the Historic Center of Lima (CHL) includes the recovery of its public spaces. In this context, various historical archeology projects are being carried out in some of its most important squares.

The main objective was to identify the different processes of renovation of these spaces, with the premise that they functioned as an integrating axis of the urban fabric of downtown Lima as dynamic social spaces since their founding times. The squares studied from their palimpsests allow us to rethink their historical memory.

From a multidisciplinary perspective, the future of the current San Francisco square was studied, from its origins at the dawn of the seventeenth century, to its current configuration as one of the most prominent and important public spaces of the CHL. The results of the historical archeology project "Plazuelas de Lima" (20192020) are presented.

keywords: historical archeology; viceregal Lima; religious architecture.

RECiBIDO: 18/02/2021 - ACEPTADO: 24/04/2021 - PublicADO: 25/06/2021

\section{BREVE HISTORIA DEL PALIMPSESTO DE SAN FRANCISCO DE LIMA}

Ya asentados en la ciudad de los Reyes desde su fundación en 1535, en 1536 la Orden Franciscana es reubicada desde sus predios originales - junto al actual convento de santo Domingo- donde se mantiene hasta la actualidad, en un terreno al pie del acantilado del entonces caudaloso río Rímac, la primera Iglesia y convento, de material rústico o "precaria ramada" Bernales (1972):

"El terreno que colindaba con la Barranca del rio, las casas de Alvino Días el conquistador, la cuadra de la carnicería y la cuadra que mira al oriente del Marques Pizarro" (Cobo, 1653 [1956]).

En 1546, luego del periodo de las guerras civiles entre españoles y sus aliados locales, los franciscanos regresaron a sus predios después de desalojar a sus vecinos, bajo la dirección del Prior Santa Ana. Ese mismo año construyendo el primer claustro del convento en el lugar donde se encuentra actualmente la plazuela y capilla de Nuestra Señora del Milagro, con los alarifes Cristóbal Burgos, Francisco de Godoy y Antonio Picado (Gento Sanz, 1945). 
En 1556 la Orden de los franciscanos obtiene la posesión de las manzanas comprendidas entre los actuales jirones Azángaro, Ayacucho, Ancash y el río Rímac para crear una manzana mayor. ${ }^{5}$ Para 1557 se inicia la construcción de la Iglesia y el claustro de San Francisco con el favor del virrey Andrés Hurtado de Mendoza, segundo Marqués de Cañete. Llegaron a tener 16 solares o 4 manzanas, incluida la llamada "huerta del Marqués Pizarro" (ídem).

En 1581 se realizan trabajos para poder llevar agua al claustro desde las fuentes coloniales (Lee, 1935). Esta empresa tuvo éxito en 1613 con la construcción de cañerías y fuentes en Lima, con agua potable desde la pila pública del Santo Oficio (Bromley, 2005). En 1603 se culmina la construcción de la primigenia Capilla de Nuestra Señora de la Soledad, siendo parte de ella ocupada inicialmente en la actual plazuela (Bernales, 1972). En 1629 se construye la llamada Capilla de la Virgen del Milagro, en conmemoración al terremoto del mismo año. Esta primera capilla fue erigida gracias a la Cofradía de Nuestra Señora de la Soledad con el permiso de los Hermanos Franciscanos para su construcción en lo que hoy conocemos como Plazuela de San Francisco.

Con esta transacción los Hermanos Soleanos consiguen mayor independencia por tener salida directa a la calle a cambio de financiar la construcción de un claustro en el interior del convento. Las referencias a esta primera capilla de la Soledad son apenas mencionadas por algunos cronistas conventuales²:

"En el mismo convento de Lima hay otra capilla con tres puertas, la una que entra a la claustra y las dos que miran a la calle y plaza del convento (que es grande y espaciosa). Enriquecen este sagrado lugar varias pinturas de pincel y labores de azulejos, que visten sus paredes. Realzan su adorno cinco altares; el principal y los dos colaterales son labrados de costosa escultura. Atesoran los medios, el principal la Imagen de N. S., de la Soledad; los colaterales el S. Crucifijo y el tercero, de valiente pincel, los gloriosos mártires y médicos $\mathrm{S}$. Cosme y S. Damián, a devoción de los cirujanos y barberos de la ciudad, que sirven la capilla; la cual es tan espaciosa y capaz, que el año de mil y seiscientos nueve sirvió de Catedral al ilustre Cabildo y sus prebendados, donde celebraban las misas y oficio divino, el tiempo que se aderezó su Iglesia, por haber quedado lastimada del gran temblor de tierra que aquel año, por el mes de octubre, padeció esta ciudad" (Fray Diego de Córdova y Salinas ,1651).

La composición de esta primera capilla difería con la actual pues contaba con una sola nave, una orientación oeste-este y un acceso lateral que era el principal. Este patrón arquitectónico coincide con las iglesias coloniales tempranas (1571-1650), de traza gótico-isabelina. Con mucha razón, el padre Antonio San Cristóbal (2006)

2. Se tiene como documento gráfico un lienzo propiedad de la Cofradía de Nuestra Señora de la Soledad, que representa la procesión de penitencia a mediados del siglo XVII, quedando re-presentada la fachada de esta primitiva capilla y su entorno arquitectónico. 
señala que dos acontecimientos históricos definen la evolución de la arquitectura en San Francisco: los seísmos de 1656 y 1687 (figura 01).

Luego del terremoto del 1656, en 1673 se inaugura el templo de San Francisco, instalándose en la torre la campana mayor. Para ese entonces la plazuela de San Francisco ya contaba con un piso empedrado (Barbagelata, 2012). De acuerdo a la obra gestionada por Fray Luis de Cervela, en baso a los planos de Constantino de Vasconcellos y la ejecución del alarife Manuel Escobar (Gento Sans, 1945), se estableció un cerco perimétrico o muro pretil en los límites de sus escaleras de ingreso provisto de balaustres y de las reconocibles 27 cruces de mármol o piedra de Berenguela, traídas de la provincia altiplánica de Pacajes (figura 02).

Tras varias disputas y litigios un espacio quedó reservado para exclusivo uso público: la hoy llamada Plazuela de San Francisco, donde se celebraron actividades populares o profanas ${ }^{3}$ como fiestas, juegos de cañas y corridas de toros, así como también ritos institucionales religiosos.

Un rasgo característico de la plazuela San Francisco es la ausencia en tiempos virreinales e incluso inicios de la República, de una fuente de agua. Como se ha expuesto líneas arriba, el sistema de canales desde el río Huatica abastecía solo el interior del convento San Francisco.

En épocas republicanas, hay registros de modificaciones en 1831, 1844, 1871, 1954 y 1987, las que tuvieron como consecuencia la pérdida del piso empedrado (circa 1844), del muro pretil en 1871, entre otras remodelaciones importantes (figura 03).

Se tiene referencias de un contrato de 1841 , donde se solicita al prefecto de Lima el uso de los arriendos del teatro principal para la remodelación de la plazuela de San Francisco y el atrio del templo con su cementerio, conforme a plano de la municipalidad de Lima y con un presupuesto de 22,384 soles de la época. ${ }^{4}$

3. Hasta 1682 se realizaron corridas de toros en la plazuela de san Francisco, hasta que fueron prohibidas por el Cabildo de Lima. También funcionó como mercado de abastos y de venta de personas en condición de esclavitud, provenientes del continente africano (Durán Montero, 1994)

4. Según las mismas referencias, las refacciones comprendían el uso de los siguientes detalles:

- 2.961 metros cuadrados de terreno que hay que terraplenar y nivelar.

- 282 metros lineales de escalones de granito para el cementerio, con sus respectivos cimientos de mampostería de cal y ladrillos con piedra.

- 295 metros lineales de filotes para las veredas laterales de los caminos, de loza inglesa, o piedra artificial.

- 1.650 metros cuadrados de piso formado con loza inglesa o piedra artificial de 0.05 de espesor colocado sobre una cama de hormigón.

- 1.000 metros cuadrados, con piedra menuda.

- 800 metros de empedrado corriente para las calles laterales.

- 44 pozas formadas con piedra artificial.

- 250 metros lineales de cañería de fierro doble para el riego de dichas pozas.

- Pila de fierro fundido con su recipiente, y cañerías de agua y desagüe.

- 12 bancos de mármol, de $2 \mathrm{~m}$ largo y $0.5 \mathrm{~m}$ ancho y de 0.05 de espesor.

- 52 metros lineales de verja para el jardín del centro, con dos puertas de reja, colocadas sobre base de piedra.

- Resanar la parte baja de la facha y costado de la Iglesia y gastos imprevistos, comprendiendo la exportación de los desmontes. 


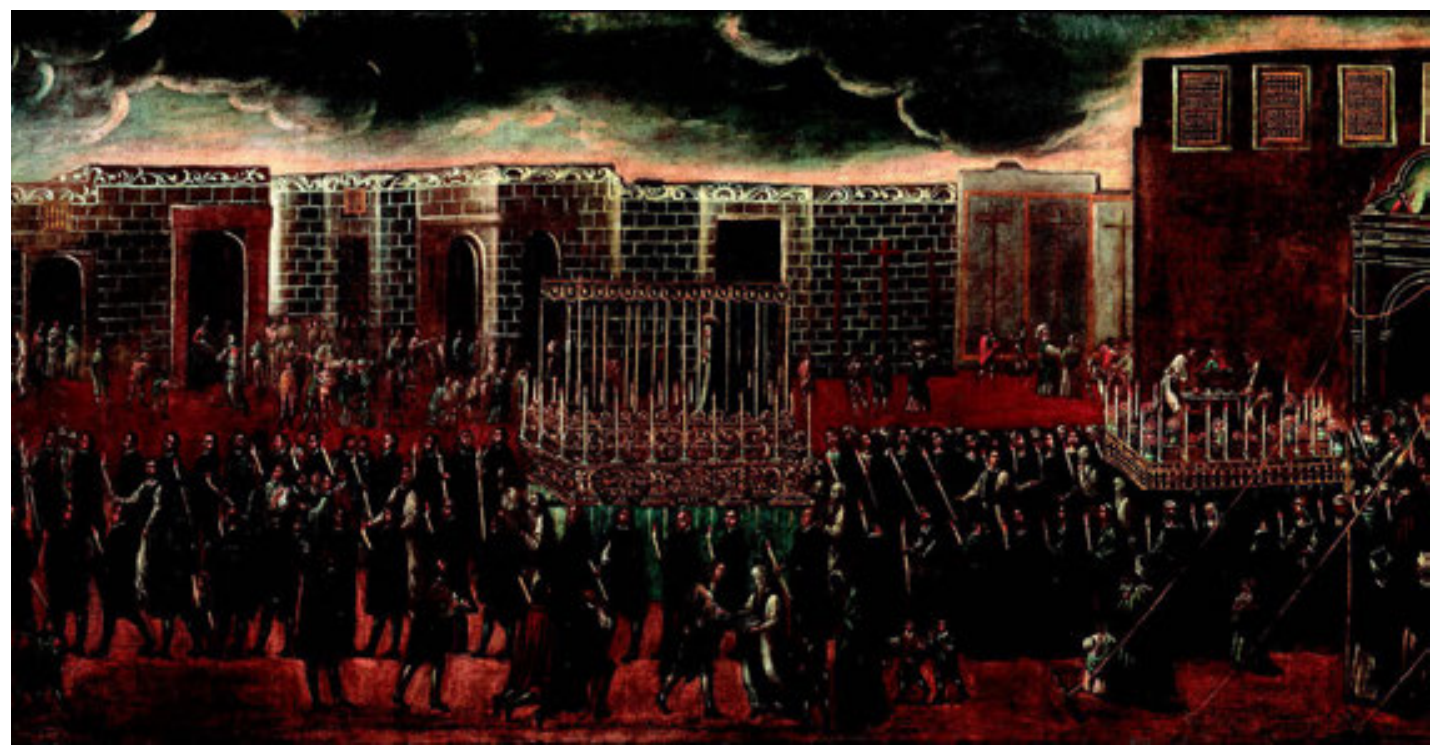

Figura 01. Detalle de Lienzo anónimo de procesión en la plazuela de san Francisco (S. XVII) Cortesía Hermanos Soleanos.

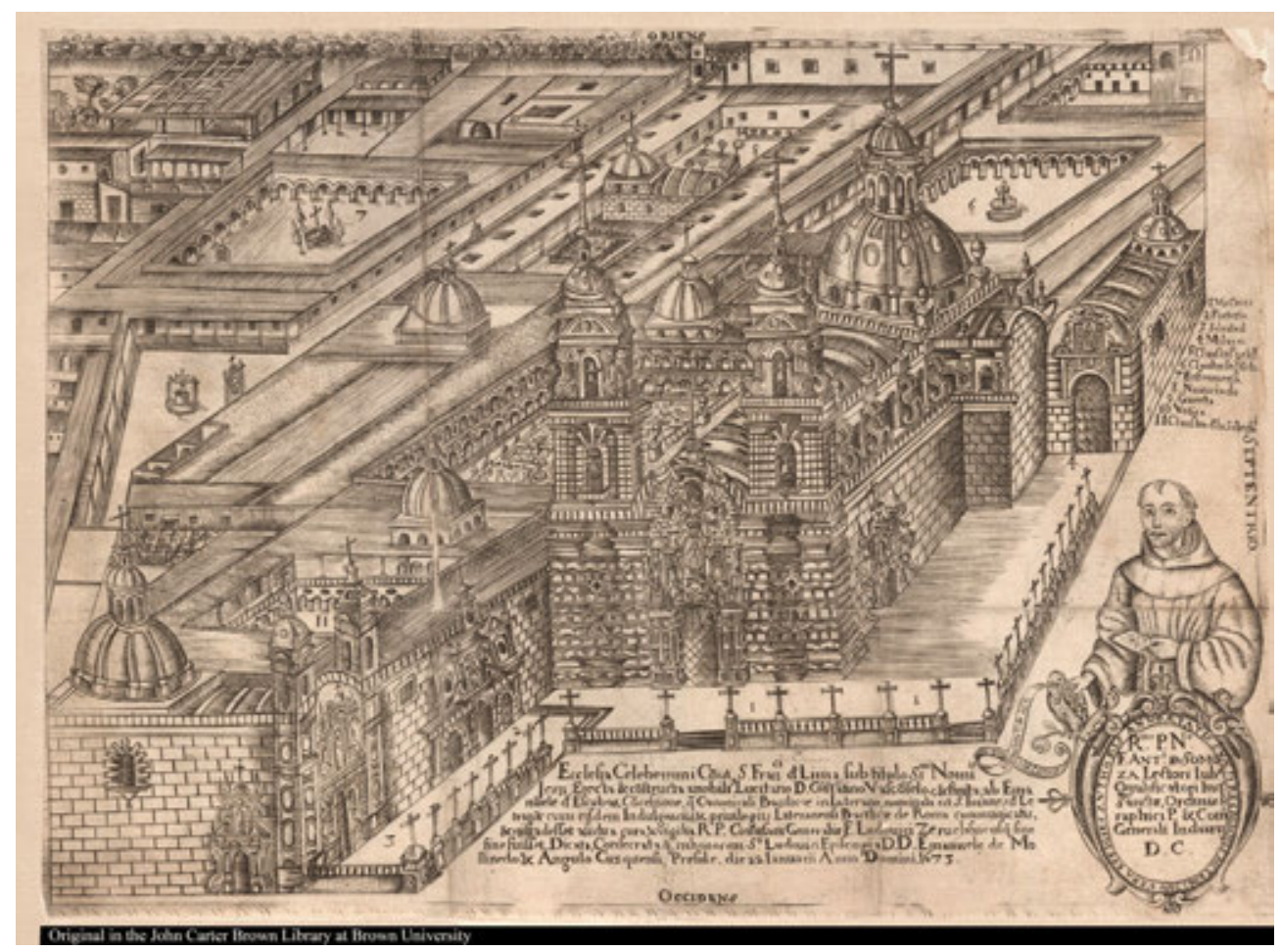

Figura 02. Iglesia San Francisco (1675) según Juan de Benavides. 


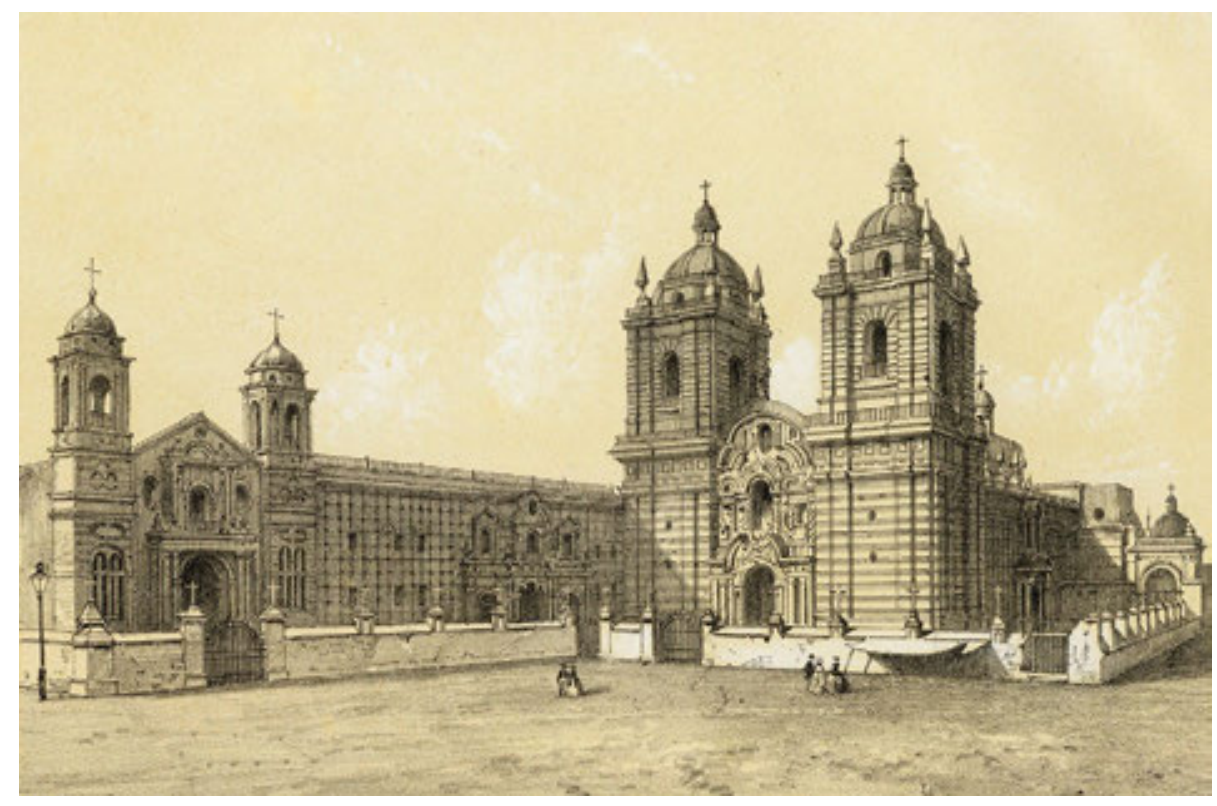

Figura 03. Plazuela de san Francisco según el Atlas de Paz Soldán (1865).

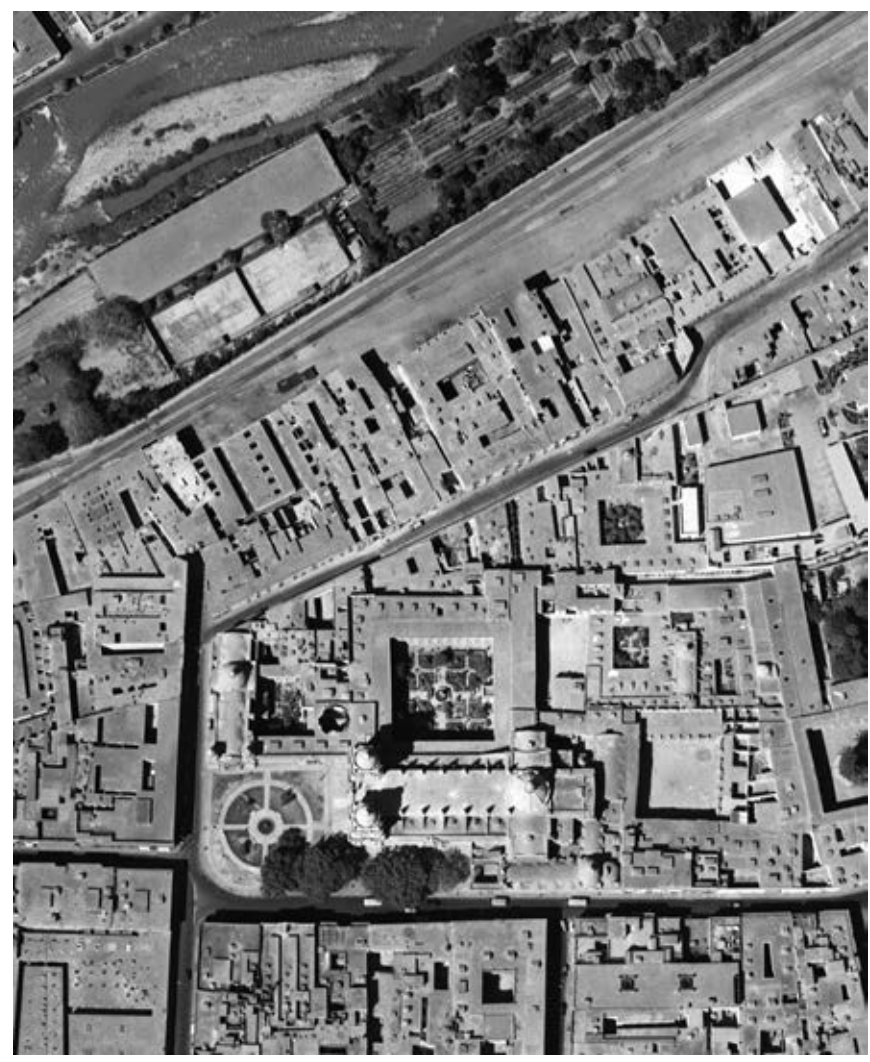

Figura 04. Zona Monumental-Religiosa de san francisco 1944 (Fuente SAN). 
En 1871, se llevó a cabo un proyecto de remodelación integral de la plazuela que consistió en demoler el perímetro de 27 cruces de berenguela para fusionar espacialmente el atrio con la plazuela en una sola plataforma de loza inglesa, o piedra artificial, según un trazo circunferencial y radial que incluyó 250 metros lineales de cañería de fierro, con una salida de agua en su centro, la misma que determinó el trazo de los planos de la nueva Plazuela y de los jardines (figura 04).

Luego de los proverbiales conflictos entre la Municipalidad de Lima y los Franciscanos, las obras de remodelación de la plazuela de San Francisco concluyeron en 1955, siendo casi la actual composición, salvo el muro perimétrico actual que separa la plazuela de la acera pública y fue construida en los años 80 del siglo pasado (figura 05).

\section{PROBLEMÁTICA Y MARCO TEÓRICO}

Para ubicar cronológicamente el periodo colonial hemos tomado a Isaac Sáenz (2007), quien identifica dos periodos a partir de la fundación de Lima hasta el terremoto de 1746: Lima fundacional (1535-1571) y Lima monástica (1571-1746). El autor precisa que a partir de la segunda mitad del siglo XVI se produce un proceso de conventualización de la ciudad, la culminación de la visión religiosa-mística y su importancia en la vida social, así como en la organización espacial de la Lima virreinal.

Es en estos periodos donde se trazan la mayoría de las plazuelas que perduran hasta hoy, incluyendo la de San Francisco, que reflejan la inicial influencia de las órdenes religiosas en la vida cotidiana y en el trazado de la Lima colonial, rompiendo desde un inicio el patrón ortodoxo del damero fundacional, creando nuevas redes de poder alternas al formado en torno de la plaza Mayor. Las plazas y plazuelas jugaron un papel crucial en el reparto y circulación de quizá el bien más preciado en una ciudad colonial, propensa a epidemias y demás males: el agua potable. Con la introducción, basado en los antiguos canales prehispánicos, de un sistema de cañerías y piletas, se favoreció grandemente la salubridad de la ciudad de Lima, lo que acrecentó la importancia estratégica de estas plazuelas.

Otro aporte importante es el que señala Gabriel Ramón (2005), para quien la característica más importante de las plazuelas es la multifuncionalidad de estas, que plasmaron también estrategias espaciales de segmentación y segregación social, las mismas que se evidencian en los usos del espacio público de estas (figura 06).

Tras las variadas funciones que van entre lo sagrado (procesiones, autos sacramentales, autos de fe, honras fúnebres) y lo profano (corrida de toros, mercados, trata de esclavos, corral de comedias), se tejen una serie de relaciones sociales que perpetúan las condiciones de opresión propia de un sistema colonial, La jerarquía espacial y dinámica social de los espacios públicos (plazas y plazuelas) hicieron que estas en tiempos virreinales tuvieran usos múltiples, complementarios a los de la Plaza Mayor (ídem). 

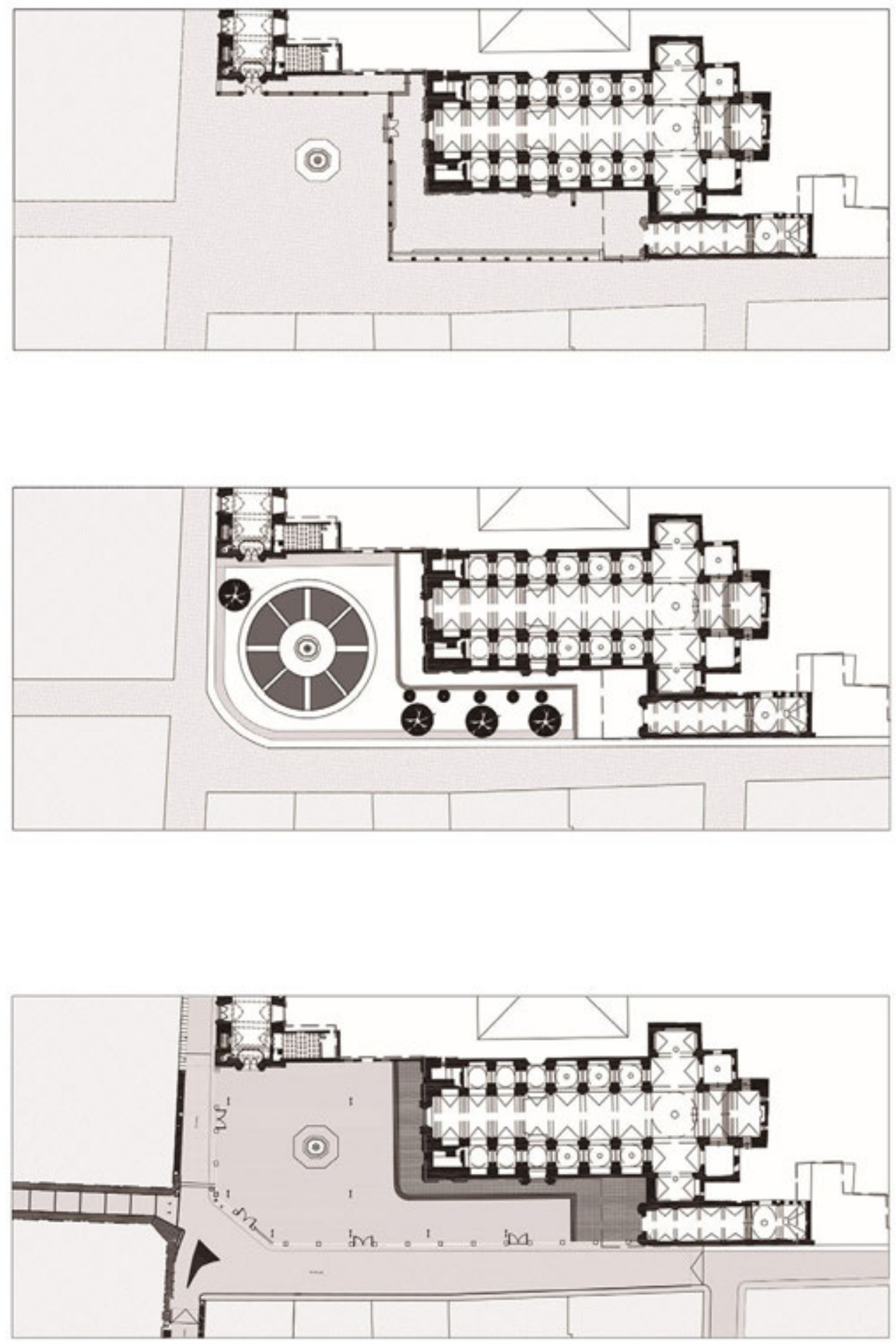

Figura 05. Evolución de la plazuela de san Francisco, Siglos XVII-XX. (Cortesía Prolima). 
Las Iglesias como sintaxis arquitectónica son un medio importante para transmitir mensajes autoreferenciales. ${ }^{5}$ En este caso particular, la iglesia, en tanto edificio eclesiástico, es un lugar de culto, construida y destinada específicamente para prácticas rituales. El ritual puede llevarse a cabo en un edificio especial reservado a funciones sagradas (Renfrew y Bahn, 1998). (figura 07).

La categoría "palimpsesto urbano"6 nos sirve para sustentar que la ciudad fundada como de los Reyes fue levantada sobre un planeamiento previo prehispánico, plasmado en las trazas de sus caminos y acequias. Su centro histórico ha conservado su traza colonial, pese a los distintos procesos sociales que ha tenido durante los casi cinco siglos transcurridos desde su fundación que han devenido en un importante testigo estratigráfico, el cual permanece en el subsuelo de las actuales edificaciones. En las plazas y plazuelas del CHL se pueden realizar con mayor eficacia estudios históricos y arqueológicos que nos ayuden a comprender y conocer la historia de la capital del Perú (figura 08).

La inclusión de la arqueología histórica en los planes de revitalización de la ciudad, ayudan a reforzar una serie de ejes estratégicos que consideran la consolidación el Paisaje Histórico Urbano, buscando realzar los valores universales excepcionales del patrimonio de Lima; haciéndolo un centro histórico habitable y atractivo con mejores condiciones de vida y fortaleciendo su carácter histórico como un centro metropolitano tradicional, cultural y vivo. ${ }^{8}$

\section{METODOLOGÍA: LA AEROFOTOGRAMETRÍA DE LAS PLAZUELAS Y LA TRIN- CHERA REVISITADA}

El levantamiento topográfico de las plazuelas y áreas circundantes tuvo como fin el registrar fidedignamente las posibles proyecciones, adiciones y asociaciones a los actuales límites de las plazuelas. Se realizó un registro aerofotogramétrico de la plazuela San Francisco para facilitar las excavaciones arqueológicas replanteadas por diversas circunstancias propias de un proyecto de investigación arqueológica.

La estrategia de excavación siguió el concepto clásico de "trincheras", las cuales, según los hallazgos obtenidos, van agrupándose hasta formar una excavación en

\footnotetext{
5. "Cada aspecto de la organización misma del diseño se convierte en figura, asume significado y expresa valores." (Dianich, 2013).

6. Morgado (2007): "Lima no fue una fundación ex novo, sino, aunque en menor escala que Cuzco o México, una fundación española sobre un asiento indígena. Producto del obstáculo que significó esta traza indígena, en Lima no se lograría conservar ni expandir la planta inicial. Es decir, se propone que la traza española de Lima se dibujó sobre una planta anterior, parte de la cual aún es legible, por lo que en Lima estamos frente a un palimpsesto urbano" (p. 78).

7. "Partimos de la premisa de que la Arqueología requiere la participación interdisciplinaria para tener una perspectiva amplia de las actividades humanas y su cultura material” (Alzate, 2011).

8. Plan Maestro del Centro Histórico de Lima 2019-2029, Resumen Ejecutivo.

9. Cada "Trinchera" estaba formada por unidades mínimas de excavación de $2 \mathrm{~m}$ x $2 \mathrm{~m}$.
} 
Papel renovador en el urbanismo virreinal.

Actores sociales dinámicos: entre lo sagrado y lo profano.

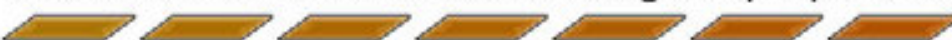

Indicador del palimpsesto de la Lima histórica.

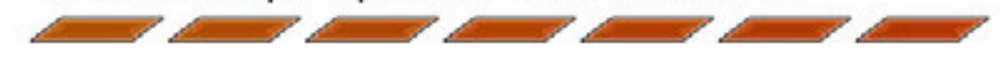

Figura 06. Características del estudio arqueológicos de las plazuelas

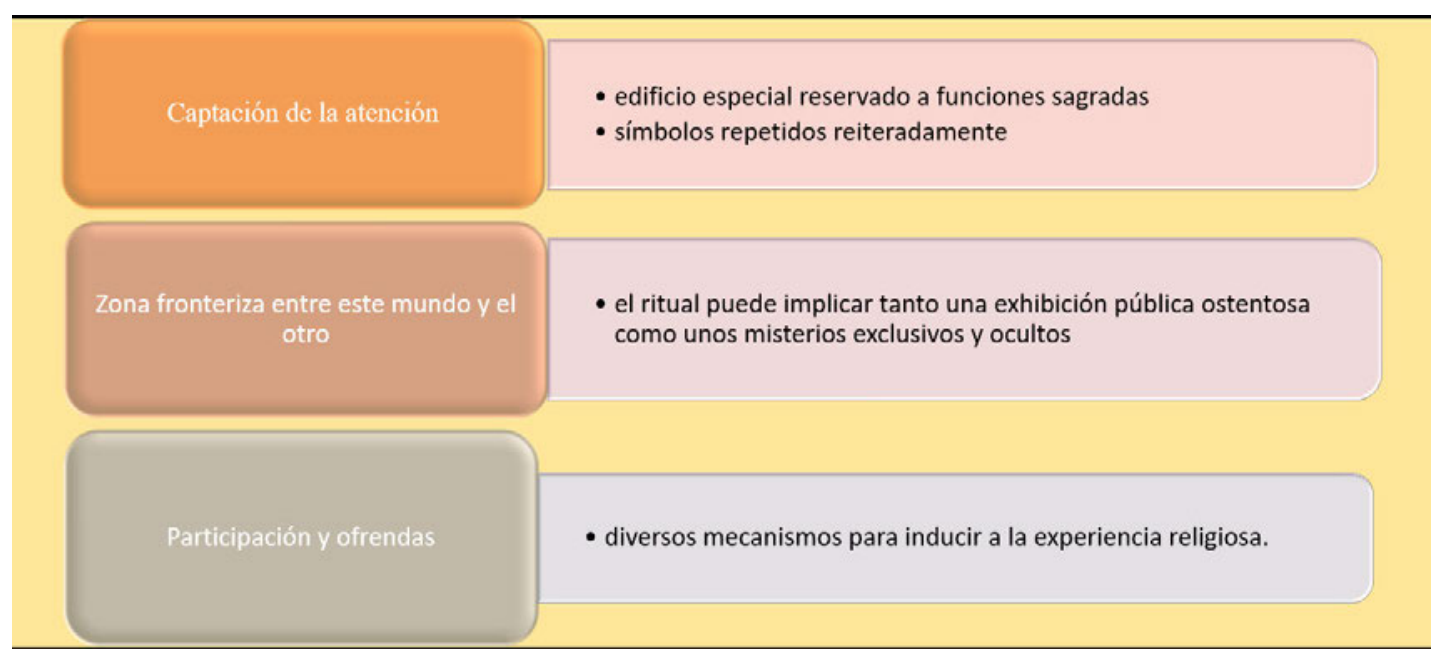

Figura 07. Indicadores arqueológicos del ritual (basado en Renfrew y Bahn, 1998).

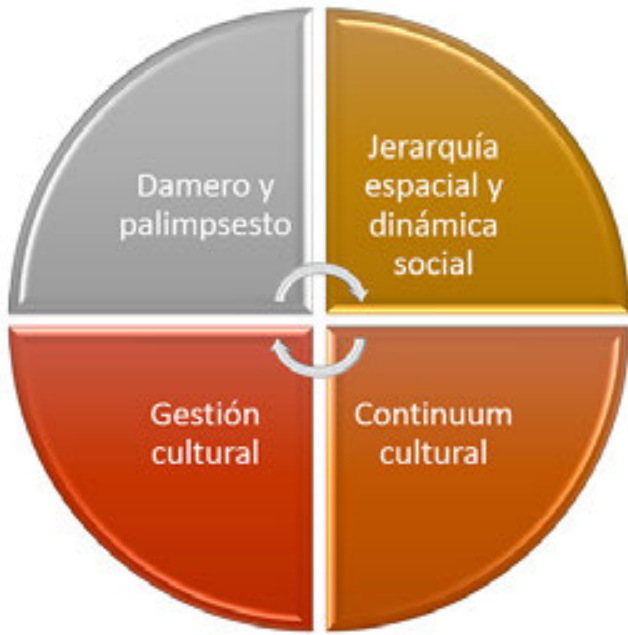

Figura 08. Ejes de la arqueología en el centro histórico de Lima. 
"área". En esta publicación trataremos los resultados de dos "trincheras" de excavación. Se utilizó el software ArcMap y tuvo como objetivo sistematizar toda la data obtenida georreferenciada en el sistema WGS84 zona 18 L, para esta labor se necesitó un levantamiento fotogramétrico obtenido mediante un dron con una resolución de $25 \mathrm{mpx}$. Luego se pasó a procesarlas en sistema WGS, para luego obtener el ortomosaico y trabajar sobre ello (figura 09).

Se utilizaron ortofotos de las "trincheras" excavadas y todas las mallas de unidades proyectadas y ejecutadas con el detalle de sus elementos obtenidos durante su excavación: el piso empedrado, parte del muro pretil, piso colonial, ladrillos coloniales, el detalle del ingreso a las criptas, los elementos del muro de la iglesia, la proyección del muro con cantos rodados, como también el detalle de la pileta fueron levantados en fotografías 3D.

\section{CONSERVACIÓN PREVENTIVA}

Se llevaron a cabo medidas de conservación preventiva y estudios preliminares por parte del equipo de conservación de PROLIMA. En el caso de nuevas estructuras expuestas a través de las excavaciones arqueológicas se realizó la consolidación necesaria y una cubierta provisional para aislarla del intemperismo hasta determinar las acciones más adecuadas para su preservación. ${ }^{10}$

\section{RESULTADOS DE LAS EXCAVACIONES ARQUEOLÓGICAS}

Se expondrán las excavaciones arqueológicas por "trinchera" (conjunto de unidades), luego por estratigrafía cultural según los espacios asociados por los elementos arquitectónicos y contextuales.

\section{Trinchera A}

Se encuentra ubicada hacia el lado noroeste de la Plazuela San Francisco, conformada por unidades de excavación de aprox. $1.80 \mathrm{~m}$ x $0.50 \mathrm{~m}$ y 18 unidades de excavación de $2 \mathrm{~m} \times 2 \mathrm{~m}$. (Figuras 10 y 11).

Estas unidades de excavación fueron distribuidas de manera adyacente al muro del actual frontis de la Iglesia de Nuestra Señora de la Soledad y se proyectaron hacia el lado sur.

Las unidades de excavación que se ubicaron en el frontis de la iglesia presentaron la siguiente estratigrafía:

Superficie: Compuesto por lajas de piedra de diversos tamaños, que forman parte del actual piso de la Plazuela San Francisco y al ser retiradas fueron numeradas para

\footnotetext{
10. En estos casos la acción más lógica es el cubrir las unidades de excavación siguiendo protocolos establecidos hasta que futuras intervenciones de puesta en valor y uso social sean aprobados, dado que las condiciones de humedad y salinidad del CHL no favorecen una exposición a la intemperie por un tiempo largo.
} 


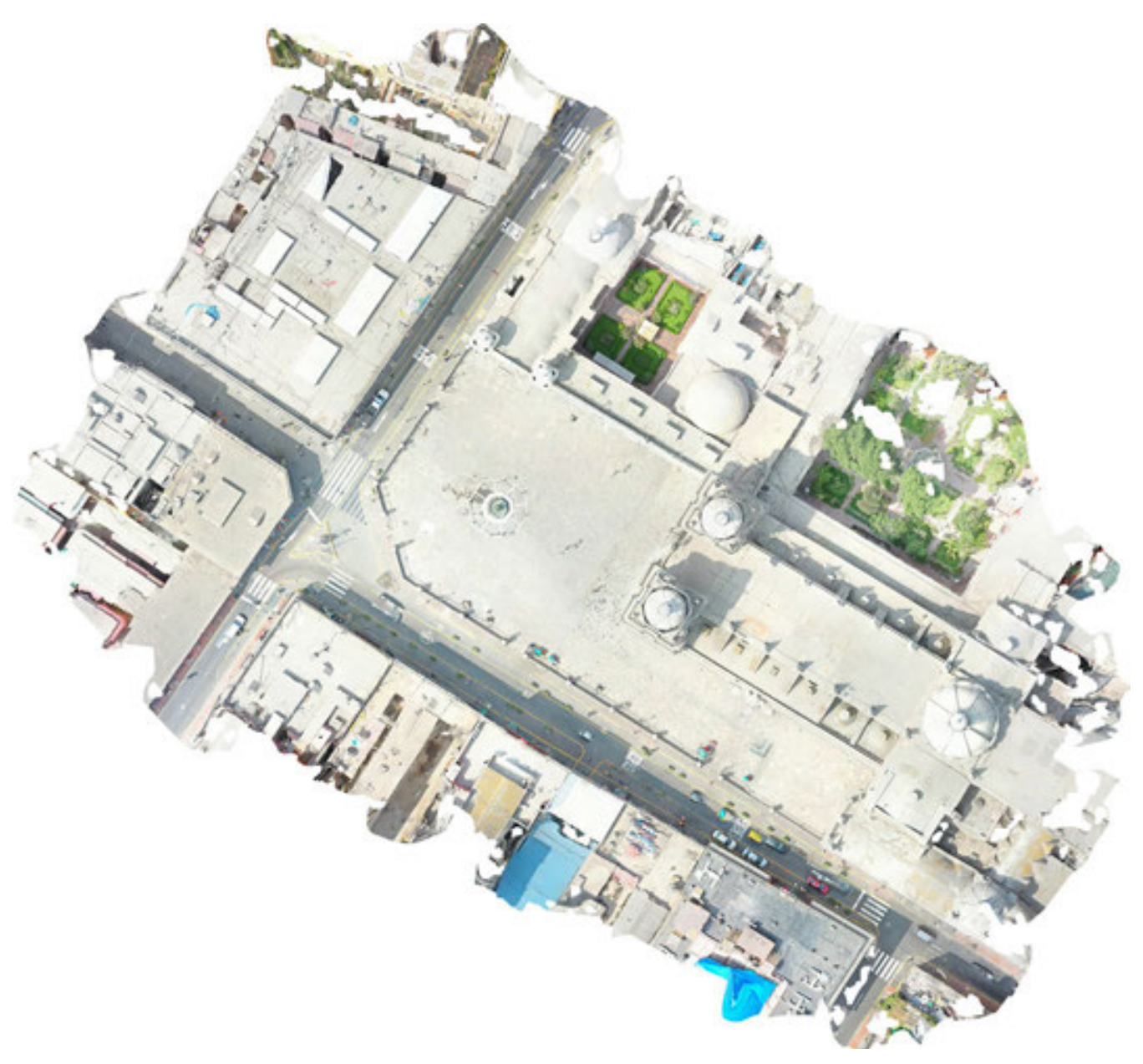

Figura 09. Ortomosaico de la plazuela de san Francisco (2019)

poder reintegrarse al final de los trabajos de excavación. Las lajas fueron asentadas sobre una capa de mortero de concreto puro mezclado con piedras pequeñas. Este nivel tiene un promedio de entre $0.08 \mathrm{~m}$ y $0.10 \mathrm{~m}$.

Capa 1: Compuesta por tierra suelta de coloración marrón oscura, con inclusiones de piedras medianas y restos de ladrillos. En las unidades 08' y 09' se reconoció los cimientos de cantos rodados y adobes que probablemente fue construido para darle soporte estructural al frontis de la iglesia. En las unidades 09', 10' y 11' en el lado norte se registró parte de un arco de descarga que fue construido por debajo de la estructura principal de la iglesia. Esta capa tiene un grosor aproximado de $0.13 \mathrm{~m}-0.50 \mathrm{~m}$.

Capa 2: La capa está conformada por restos de adobes enteros y fragmentados que se depositaron en el lado sur del frontis de la iglesia sin un orden aparente. Estos adobes estaban mezclados con pedrería menuda y tierra semicompacta. En las 
unidades 09', 10' y 11' se logró definir los límites del arco de descarga que se apoya sobre una hilera de ladrillos que fueron colocados en un hoyo rectangular. Este hoyo ha cortado la superficie del nivel inferior y fue cubierto por tierra y piedras pequeñas. Tiene un grosor aproximado de $0.27 \mathrm{~m}-0.45 \mathrm{~m}$.

Capa 3: En las unidades 10' y 11' se registró tierra marrón claro de consistencia suelta, mezclada con pedrería menuda en mínima proporción y restos de ladrillo de pequeñas dimensiones. Esta capa cubría el piso que funciono como techo de la bóveda. Tiene un grosor de aproximadamente $0.10 \mathrm{~m}$.

Apisonado: compuesto de barro de coloración marrón oscuro y consistencia compacta.

En las unidades 09', 10' y 11' en el lado norte de las unidades se registró un corte en el apisonado de barro. En este corte, se evidenció tierra de consistencia suelta y calicanto que cubría una hilera de ladrillos. Al retirar parte de estos ladrillos en la unidad 09' se registra una bóveda de gran tamaño que se extiende hacia los lados sur, este y oeste de la Plazuela de San Francisco. Se realiza un corte arbitrario en el piso de barro en el lado norte, descubriéndose el techo de la bóveda y restos de calicanto. A este nivel se dio por finalizada la excavación.

En las unidades ubicadas en el lado sur de la Iglesia de Nuestra Señora de la Soledad se reconocieron los siguientes niveles estratigráficos:

Superficie: Está conformada por lajas de piedra de diferentes tamaños, estas lajas forman parte del actual piso de la Plazuela San Francisco y fueron numeradas para poder reintegrarse al final de los trabajos de excavación. Las lajas fueron colocadas sobre mortero de concreto puro mezclado con piedras pequeñas. Debajo de este mortero se registra un solado de concreto que se colocó sobre la capa 1. Este nivel tiene un promedio de entre $0.14 \mathrm{~m}$ y $0.16 \mathrm{~m}$.

Capa 1: Compuesta por tierra suelta de coloración marrón oscura, con inclusiones de piedras medianas y restos de ladrillos. En esta capa se registró gran cantidad de material cultural mezclado con basura moderna. Hacia las unidades 31, 32, 33, 54, 55 y 56 se registró un muro de aproximadamente $0.44 \mathrm{~m}$ de alto y $0.55 \mathrm{~m}$ de ancho. Este muro está hecho de ladrillos de $0.29 \mathrm{~m}$ de largo por 0.14 de ancho y se proyecta hacia el lado este de la Plazuela San Francisco. Se puede diferenciar la construcción de ladrillos en aproximadamente $2.22 \mathrm{~m}$ de largo, mientras que $3.34 \mathrm{~m}$ hacia el lado este, fue construido con piedras canteadas de mediano tamaño. Además, presenta restos de enlucido naranja, amarillo y rojo. Esta capa tiene un grosor variable que va entre $0.40 \mathrm{~m}$ a $0.50 \mathrm{~m}$.

Capa 2: Esta capa está conformada por tierra semicompacta y restos de ladrillos y cantos rodados de mediano tamaño que se depositaron sin un orden aparente hacia el lado sur de las unidades 30 y 31, y hacia el lado norte de las unidades 53, 54 y 55. 


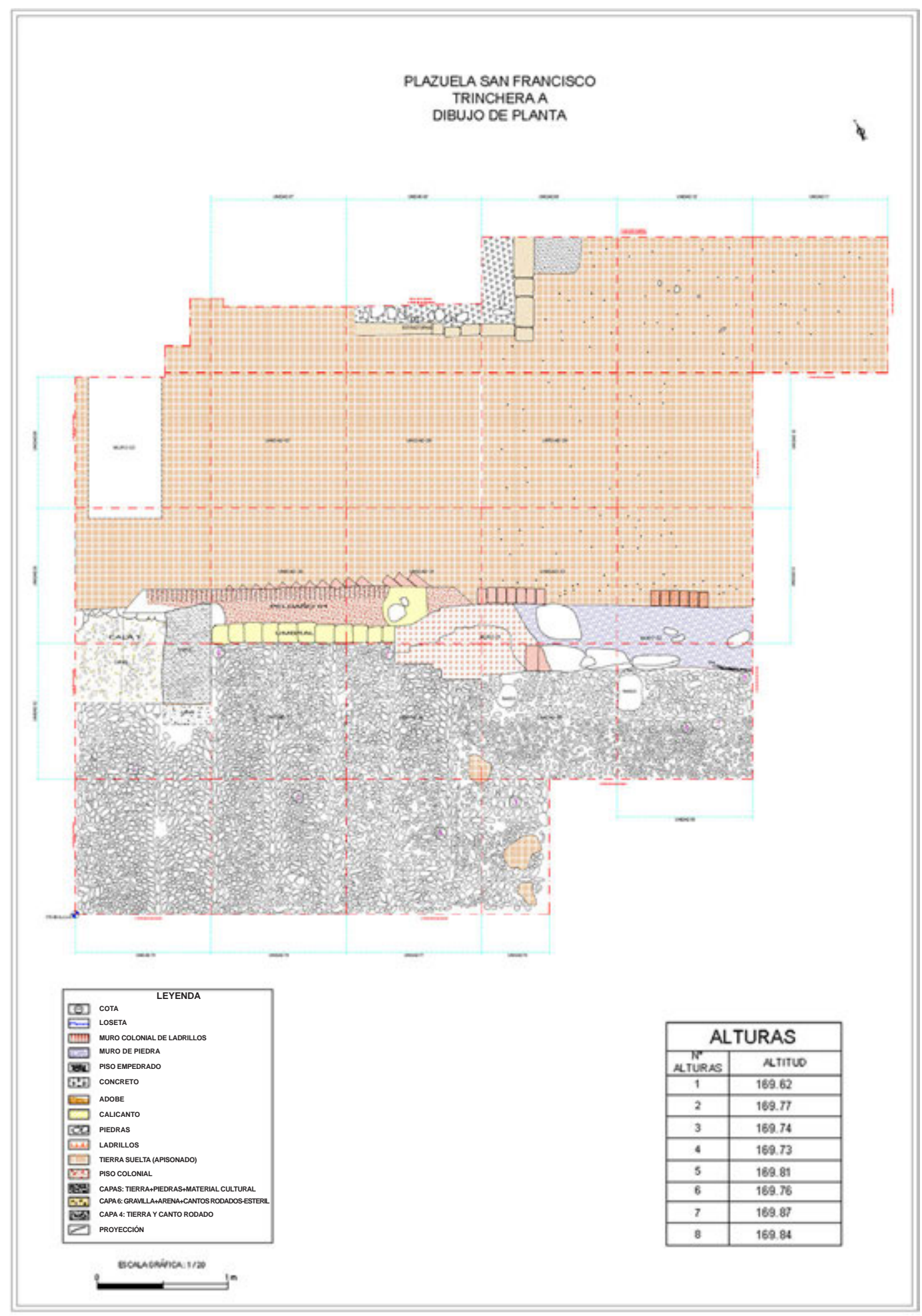

Figura 10. Plano de planta general de la trinchera $A$. 


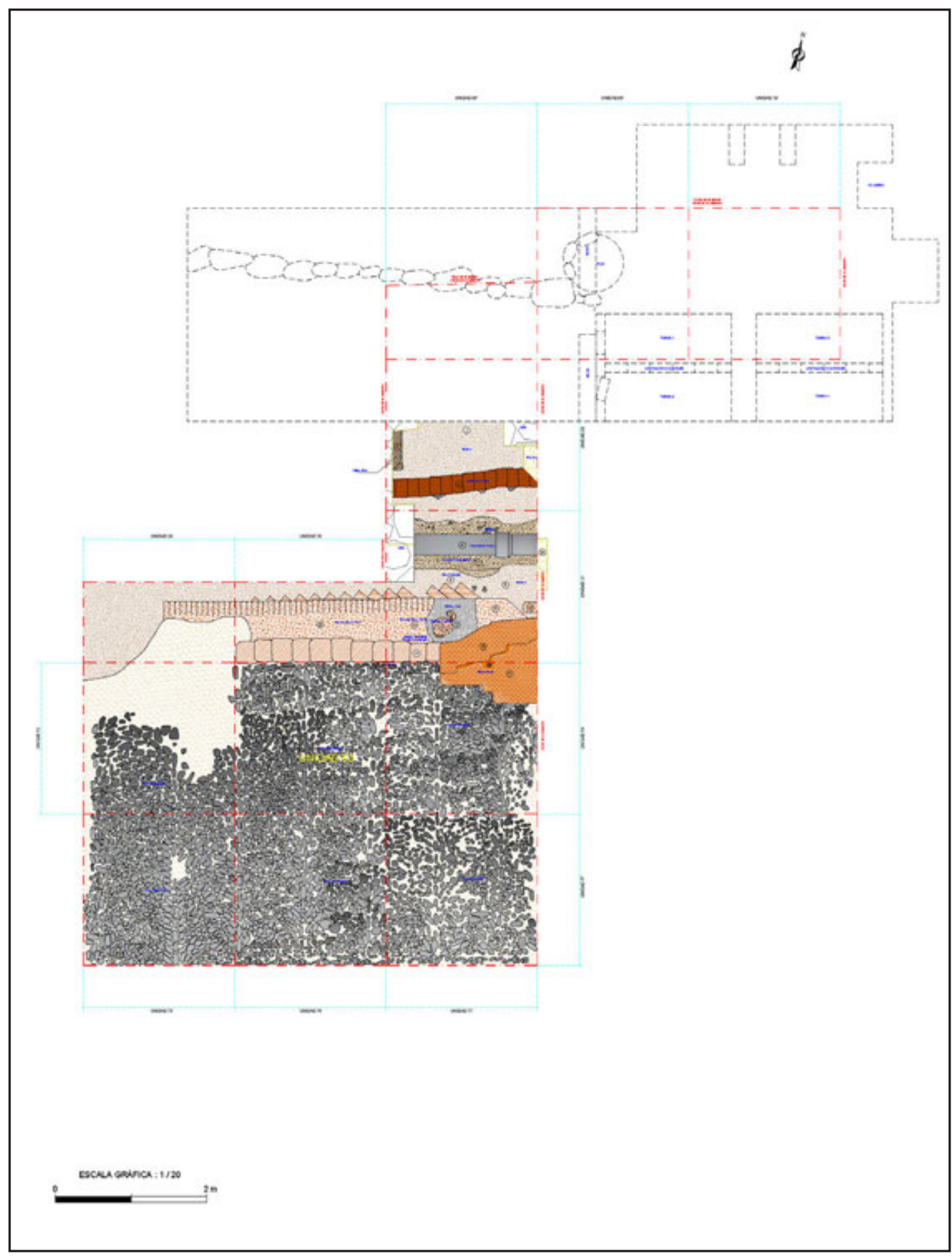

Figura 11. Plano de la trinchera A con el interior de la cripta sepulcral. 
Estos cantos rodados estaban cubriendo una hilera de adoquines de calicanto, que habrían sido colocados delimitando un vano de acceso, de $5.05 \mathrm{~m}$ de largo por 0.53 $m$ de ancho.

Este acceso tiene un peldaño que era utilizado para acceder al espacio delimitado en otras unidades. En la unidad 31 se reconoció un quicio de $0.68 \mathrm{~m}$ por 0.61 $\mathrm{m}$ que intruyó en la superficie del peldaño. Esta capa tiene un grosor aproximado de $0.27 \mathrm{~m}-0.45 \mathrm{~m} .{ }^{11}$

Piso Empedrado: Superficie de uso, construida con cantos rodados de pequeño tamaño (entre $0.05 \mathrm{~m}$ y $0.08 \mathrm{~m}$ ) dispuestos ordenadamente formando figuras posiblemente fitomorfas y separadas por líneas entre cada diseño. Estos guijarros eran colocados a junta seca y se caracterizaban por tener dimensiones y tonalidades de colores similares. Hacia la unidad 54 se puede reconocer la base del muro reconocido desde la capa 1, y está asociado al piso empedrado. En las unidades 29 y 30 se reconoce un segundo quicio intruido en el peldaño, correspondiente al marco de la puerta de acceso. En las unidades 29 y 52 no se ha logrado conservar este piso empedrado, ya que el terreno ha sido bastante removido por las diferentes construcciones de épocas actuales. Este piso se reconoce a una profundidad de 0.70 y $0.85 \mathrm{~m}$.

Con la finalidad de entender la secuencia constructiva de la Plazuela de San Francisco, se realizó una cala exploratoria donde se reconocieron los siguientes niveles estratigráficos:

Capa 3: Compuesta por tierra suelta de coloración marrón oscura, con inclusiones de piedras pequeñas. Esta capa habría funcionado como un apisonado sobre el cual se colocaron ordenadamente los cantos rodados, formando diversos diseños. Tiene un grosor promedio de $0.28 \mathrm{~m}$ y al interior no se registró material cultural. Hacia el lado este se reconoció una delgada capa de calicanto que se proyecta por debajo del umbral y hacia el lado oeste se reconoce un lente de limo de un grosor aproximado de $0.20 \mathrm{~m}$.

Capa 4: Esta capa está compuesta por una gran cantidad de cantos rodados de diversos tamaños, mezclado con una mínima cantidad de tierra suelta. Tiene un grosor promedio de $0.30 \mathrm{~m}$ y al interior se reconoció una mínima proporción de material cultural: restos de cerámica, algunos fragmentos de metal y fragmentos óseos.

Capa 5: Está conformada por tierra de color marrón claro y consistencia semicompacta mezclada con piedras pequeñas en mediana proporción. Tiene un grosor promedio de $0.30 \mathrm{~m}$ y entre el material registrado, se reconocieron dos fragmentos de cerámica estilo "inca local". 
Capa 6: Esta capa corresponde a una mezcla de gravilla, arena y cantos rodados, material propio de lecho de río. Tiene consistencia suelta y coloración amarillenta. Se excavó un promedio de $0.48 \mathrm{~m}$, donde se dio por finalizada la excavación.

Hacia el lado oeste de esta cala se registraron las bases y uno de los paramentos de un muro de ladrillos. Este muro se extiende hacia el oeste y habría formado parte del antiguo frontis de la Iglesia de Nuestra Señora de la Soledad.

Hacia el lado central de las unidades 55 y 56 se reconoció el Rasgo 01, que estaba compuesto por ceniza apoyada en el piso empedrado y estaba distribuida en $0.40 \mathrm{~m}$ de largo y $0.60 \mathrm{~m}$ de ancho. Al interior de este raso no se registró material cultural.

\section{Trinchera D}

Se encuentra ubicada en el lado oeste de la Plazuela San Francisco, conformada por siete unidades de excavación de $2 \mathrm{~m} \times 2 \mathrm{~m}$ y tres unidades de excavación de $1.00 \mathrm{~m} \times 2.00 \mathrm{~m}$. Estas unidades fueron ubicadas de forma adyacente al actual muro perimétrico de la Plazuela San Francisco y se proyectan hacia el lado este. Las unidades de excavación para esta área son las siguientes: 01', 02', 03', 01, 02, 03, 24, 25, 47 y 48 . (Figura 12).

En las unidades 24, 25, 47 y 48 se han reconocido las siguientes capas estratigráficas:

Superficie: Está conformada por lajas de piedra de diferentes tamaños que forman parte del actual piso de la Plazuela San Francisco. Estas lajas fueron numeradas para poder reintegrarse al final de los trabajos de excavación. y fueron colocadas sobre mortero de concreto puro mezclado con piedras pequeñas. Debajo de este mortero se registra un solado de concreto que se colocó sobre la capa 1. Este nivel tiene un promedio de entre $0.13 \mathrm{~m}$ y $0.15 \mathrm{~m}$.

Capa 1: Compuesta por tierra suelta de coloración marrón oscura, con inclusiones de piedras y fragmentos de ladrillos. En esta capa se registró mediana cantidad de material cultural conformado por fragmentos de botija, azulejos y objetos de metal. Hacia las unidades 47, 48, 24 y 25 se registró un muro de aproximadamente 0.70 $\mathrm{m}$ de alto y $0.35 \mathrm{~m}$ de ancho. Este muro está hecho de ladrillos de $0.30 \mathrm{~m}$ de largo por 0.15 de ancho y se proyecta hacia el lado este de la Plazuela San Francisco.

Se puede diferenciar la construcción de ladrillos en aproximadamente $0.82 \mathrm{~m}$ de largo, mientras que $3.18 \mathrm{~m}$ hacia el lado este, fue construido con piedras canteadas de mediano tamaño y grandes cantos rodados unidos con una mezcla de cal cubrían la cabecera de este. La estructura se proyecta hasta las unidades 24 y 25 , donde se reconoce otro muro de ladrillos construido a modo de apoyo. Tiene $3.90 \mathrm{~m}$ de largo por $0.70 \mathrm{~m}$ de ancho y la técnica constructiva empleada es similar, ambos paramentos están hechos de ladrillos que fueron enlucidos y el relleno del muro está conformado por cantos rodados de mediano tamaño mezclados con cal. 
Hacia el lado oeste de esta unidad se registra la esquina de una estructura que se proyecta hacia el lado norte. El grosor promedio de esta capa es de $0.10 \mathrm{~m}$ y $0.34 \mathrm{~m}$.

Capa 2: Está conformada por cantos rodados de diferentes tamaños colocados en las unidades 47 y 48. Estas piedras fueron distribuidas a modo de relleno, sin un orden aparente. En la superficie de esta capa se puede diferenciar un hoyo que fue cubierto con cantos rodados. Esta capa tiene un grosor promedio de 0.45 y $0.60 \mathrm{~m}$.

Capa 3: Compuesta por tierra de color marrón oscuro con tonalidades blanquecinas, es de consistencia semicompacta y esta mezclada con cal y una mínima proporción de cantos rodados de pequeño y mediano tamaño. Al interior de esta capa se registró una mínima proporción de material cultural. Esta capa fue colocada a modo de revestimiento del piso empedrado. Se logró definir la superficie del hoyo que estaba adosado al sobrecimiento del muro registrado en las unidades 47 y 48 . Tiene un grosor promedio de $0.04 \mathrm{~m}$ y $0.06 \mathrm{~m}$.

Piso Empedrado: Superficie de uso, construida con cantos rodados de pequeño tamaño (entre $0.10 \mathrm{~m}$ y $0.13 \mathrm{~m}$ ) dispuestos ordenadamente, separadas por líneas entre cada diseño. Estas piedras eran colocadas a junta seca y se caracterizaban por tener dimensiones y tonalidades de colores similares. Este piso fue reconocido en las unidades 47 y 48 , fue registrado a una profundidad de $1.15 \mathrm{~m}$. A este nivel se dio por finalizada la excavación.

Hoyo 1: fue registrado hacia el lado norte de las unidades 47 y 48 mide aproximadamente 1.05 de largo (oeste-este) y $0.66 \mathrm{~m}$ de ancho (norte-sur) y de acuerdo con las evidencias recuperadas, podría corresponder a un depósito de deshechos. Se reconocieron las siguientes unidades estratigráficas:

Superficie: Cubierta por cantos rodados de diferentes tamaños, correspondientes a la capa 2. Esta capa tiene un grosor promedio de $0.16 \mathrm{~m}$.

Capa 1: Conformada por tierra de color marrón y consistencia suelta. Al interior de esta capa se registran cantos rodados de mediano tamaño dispuestos alrededor del hoyo. En esta capa se registró gran cantidad de material cultural: restos óseos animales, fragmentos de cerámica doméstica y algunos fragmentos de cerámica decorada. La capa 1 tiene un grosor de $0.50 \mathrm{~m}$.

Capa 2: Esta capa está compuesta por ceniza, de tonalidad oscura y consistencia compacta. En la superficie de esta capa se registra la base de una vasija pequeña. Al interior de la capa se registraron algunos fragmentos óseos con evidencia de quema y restos de cerámica. Esta capa tiene un grosor de $0.14 \mathrm{~m}$ y $0.18 \mathrm{~m}$.

Capa 3: Está conformada por tierra de color marrón claro, de consistencia semicompacta mezclada con piedras pequeñas. Al interior de la capa se registró una mínima proporción de fragmentos de cerámica. La capa 3 tiene un grosor de $0.17 \mathrm{~m}$. 


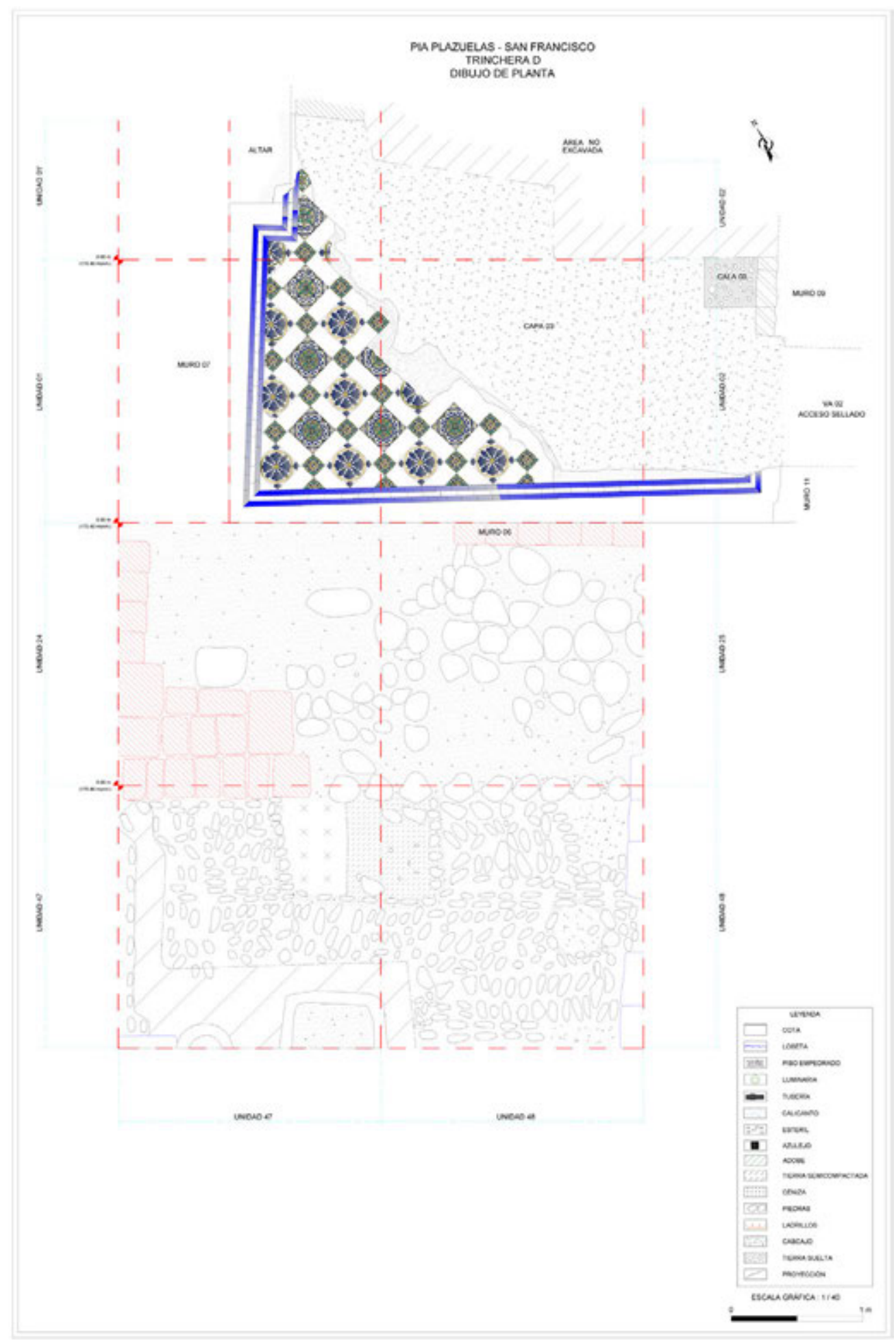

Figura 12. Plano de planta general de la Trinchera $D$. 
Capa 4: Esta compuesta por arena gruesa de color marrón, consistencia suelta y textura media, mezclada con pedrería menuda (cascajo). En esta capa no se registró material cultural y a este nivel, se dio por finalizada la excavación, a una profundidad promedio de $1.00 \mathrm{~m}$.

En las Unidades 01', 02', 03', 01, 02 y 03 la estratigrafía es la siguiente:

Superficie: Está conformada por lajas de piedra de diferentes tamaños que forman parte del actual piso de la Plazuela San Francisco. Estas lajas fueron colocadas sobre mortero de concreto puro mezclado con piedras pequeñas. Este nivel tiene un promedio de entre $0.16 \mathrm{~m}$ y $0.20 \mathrm{~m}$.

Capa 1: Conformada por tierra de color marrón, consistencia suelta y textura media. Al interior de esta capa se registra una gran cantidad de fragmentos de ladrillos, mezclado con abundante material cultural: fragmentos de cerámica terracota, vidriada y varios fragmentos de azulejos. Al ir retirando esta capa se reconocen los límites de un recinto cuadrangular con un vano de acceso que se proyecta al este, hacia la bóveda sepulcral registrada en la Trinchera A. Este recinto se registró por debajo del nivel original de la Capilla Primitiva de la Soledad, y en los cuatro paramentos internos de los muros limítrofes se reconocen improntas de azulejos y algunos azulejos distribuidos uniformemente. Hacia el lado oeste de estas unidades se reconoce un ventanal y dos arcos, uno que se proyecta hacia el este y otro hacia el lado norte. La capa 1 tiene un grosor promedio de 2.60 y $2.70 . \mathrm{m}$.

Rasgo 2: Capa de tierra de consistencia semicompacta y color marrón claro, con gran cantidad de fragmentos de azulejos colocados sobre el piso de azulejos. Este rasgo se extendió por todo el recinto y "cubrió" los niveles inferiores a modo de "sello". Tiene un grosor de $0.30 \mathrm{~m}$ aproximadamente.

- Piso de azulejos: Superficie de uso, distribuida en la UE $01,01^{\prime}, 02$ y 03 . El piso está compuesto por azulejos de $0.13 \mathrm{~m}$ x $0.13 \mathrm{~m}$ y ladrillos pasteleros de $0.27 \mathrm{~m}$ de largo x $0.14 \mathrm{~m}$ de ancho y $0.02 \mathrm{~m}$ de espesor. Otros azulejos con diseños florales fueron ordenados formando bloques de $0.26 \mathrm{~m} \times 0.26 \mathrm{~m}$ y hacia los límites del recinto se registran líneas de listelos de color azul y blanco. El piso de azulejos y ladrillo pastelero tiene un grosor de $0.02 \mathrm{~m}$ y $0.04 \mathrm{~m}$.

- Capa 2: Capa de tierra, de consistencia semicompacta, textura fina y coloración marrón claro, mezclada con restos de calicanto usado para el asentado del piso de azulejos y el ladrillo pastelero. Esta capa solo se registró hacia el este de las unidades 2 y oeste de la unidad 3. Al interior se registró gran cantidad de fragmentos de azulejos propios de la decoración del recinto. Tiene un grosor promedio de $0.03 \mathrm{~m}$. Debajo de esta capa 2 se registró una superficie uniforme de calicanto (Capa 3) y hacia el lado este se realizó una cala (Cala 2) para determinar los niveles inferiores. 
Las capas registradas en esta cala son:

Capa 3: Capa de calicanto, de consistencia compacta, textura fina y coloración blanquecina, sirvió de apisonado para la colocación del piso de azulejos con el mortero de calicanto. Tiene un grosor de $0.04 \mathrm{~m}$.

Capa 4: Capa de arena, cantos rodados pequeños y medianos, correspondiente a la capa natural. Se excavó $0.18 \mathrm{~m}$ donde se dio por concluida la excavación.

\section{ELEMENTOS ARQUITECTÓNICOS Y CONTEXTUALES}

Se presentan los elementos arquitectónicos y contextuales registrados exclusivamente en las áreas arriba mencionadas:

Muro 01: se encuentra ubicado en la Trinchera A, en el lado sur de las unidades 31 y 32 y el lado norte de las unidades 54 y 55 . Es una estructura de planta rectangular, que se orienta de NO-SE. Tiene $2.22 \mathrm{~m}$ de largo, un ancho de $110 \mathrm{~m}$ y una altura promedio de $0.53 \mathrm{~m}$. Hacia el lado sur se asienta sobre el piso empedrado mientras que al lado norte se asienta sobre un peldaño (Peldaño 01) y el piso pastelero. Está hecho de ladrillos unidos con calicanto, dispuestos a modo de soga y cabeza. Estos ladrillos tienen un tamaño promedio de 0.29 de largo, $0.14 \mathrm{~m}$ de ancho y $0.05 \mathrm{~m}$ de espesor, Hacia el paramento norte se registran posibles improntas de azulejos decorativos.

Muro 02: se encuentra ubicado en la Trinchera A, hacia el lado sur de las unidades 32 y 33 y hacia el lado norte de las unidades 55 y 56 . Es una estructura de planta rectangular, que se adosa al Muro 0 y se orienta al NO-SE. Tiene $3.34 \mathrm{~m}$ de largo, un ancho de $0.90 \mathrm{~m}$ y una altura promedio de $0.32 \mathrm{~m}$. Hacia el lado sur se asienta sobre el piso empedrado mientras al lado norte se asienta sobre un peldaño (Peldaño 02) y el piso pastelero. Está hecho de piedras canteadas unidas con un mortero de calicanto y tierra, posee mampostería ordinaria. Estas piedras miden 0.40 de largo, $0.40 \mathrm{~m}$ de alto y $0.14 \mathrm{~m}$ de ancho; hacia el paramento norte se puede diferenciar un revestimiento o enlucido y algunas posibles improntas de azulejos decorativos.

Muro 03: ubicado en la Trinchera A, en el lado oeste de la unidad 06. Es una estructura de planta rectangular, que se orienta de NO-SO. Tiene $1.82 \mathrm{~m}$ de largo y un ancho de $1.08 \mathrm{~m}$ no es posible determinar la altura ya que se descubrió la cabecera del mismo y se dio por finalizada la excavación. Está conformado por ladrillos de un tamaño promedio de 0.28 de largo, $0.14 \mathrm{~m}$ de ancho y $0.06 \mathrm{~m}$ de espesor, unidos con calicanto. Hacia el lado suroeste el muro fue roto por una intrusión moderna.

Muro 04: ubicado en la Trinchera D, en el lado sur de la unidad 24.

Estructura de planta rectangular, que se orienta de NO-SE. Tiene 1,22 m de largo, un ancho de $0.81 \mathrm{~m}$ y una altura promedio de $0.76 \mathrm{~m}$. Hacia el lado sur se asienta sobre el piso empedrado, mientras que al lado norte se apoya en el Muro 06 (M06). Está 
hecho de ladrillos de 0.29 de largo, $0.14 \mathrm{~m}$ de ancho y $0.06 \mathrm{~m}$ de espesor, están unidos con mortero de calicanto y dispuestos a modo de soga y cabeza. Estos ladrillos tienen un tamaño promedio de 0.29 de largo, $0.14 \mathrm{~m}$ de ancho y $0.05 \mathrm{~m}$ de espesor.

Muro 05: se encuentra ubicado en la Trinchera D, hacia el lado sur de las unidades 24 y 25. Es una estructura de planta rectangular, que se adosa al Muro 04. Tiene una orientación NO-SE y sus dimensiones actuales varían entre los $2.50 \mathrm{~m}$ de largo, un ancho de $0.80 \mathrm{~m}$ y una altura promedio de $0.78 \mathrm{~m}$. Hacia el lado sur se asienta sobre el piso empedrado, mientras al lado norte se apoya al paramento sur del Muro 06. La cabecera del muro está cubierta de cantos rodados de gran tamaño, mientras que en las hiladas inferiores se puede notar piedras canteadas unidas con un mortero de calicanto y tierra, dispuestas a modo de mampostería ordinaria. Estas piedras miden 0.62 de largo, $0.20 \mathrm{~m}$ de alto y $0.34 \mathrm{~m}$ de ancho; hacia el paramento norte se puede diferenciar un revestimiento o enlucido de coloración crema.

Muro 06: ubicado en la Trinchera D, en el lado norte de las unidades 24 y 25. Es una Estructura de planta rectangular, que se orienta NO-SE. Tiene $3.52 \mathrm{~m}$ de largo, un ancho de $0.95 \mathrm{~m}$ y una altura promedio de $2.68 \mathrm{~m}$, funciona como muro perimétrico ya que forma parte de un recinto de planta cuadrangular que se ubicó debajo del altar mayor de la "capilla primitiva" de la Soledad. Se asienta sobre un piso de azulejos y ladrillos pasteleros. Hacia el lado norte se adosa al Muro 07, mientras que hacia el lado sur se le adosa el Muro 11. Está hecho de ladrillos unidos con mortero de calicanto, hacia el paramento norte del muro se reconoce un enlucido de color crema de $0.97 \mathrm{~m}$ de alto, y en la sección inferior del muro se reconocen restos de azulejos y restos de calicanto, que forman parte de las improntas de los mismos azulejos, distribuidos en 1,67 m de alto. Debajo de estas improntas se registran piedras angulares y algunos fragmentos de cerámica, que forman parte del revestimiento del paramento, previo a la colocación de los azulejos. El interior del muro tiene cantos rodados de gran tamaño, asentados con mortero de calicanto.

Muro 07: se encuentra ubicado en la Trinchera D, en el lado norte de la unidad 24 y el lado sur de la unidad 01. Es una Estructura de planta rectangular, que se orienta de SO-NE. Tiene $2.34 \mathrm{~m}$ de largo, un ancho de $0.89 \mathrm{~m}$ y una altura promedio de 1.61 $\mathrm{m}$, funciona como muro perimétrico ya que forma parte de un recinto de planta cuadrangular que se ubicó debajo del altar mayor de la "capilla primitiva" de la Soledad. Se asienta sobre un piso de azulejos y ladrillos pasteleros. Hacia el lado sur se le adosa el Muro 06, mientras que hacia el lado norte se apoya en el Arco 02. Sobre este muro se construyó una plataforma de ladrillos donde se asienta un ventanal (Ventanal 01), el Muro 12 (M12) y los Arcos 01 y 02. El muro esta hecho de ladrillos unidos con mortero de calicanto. Hacia el paramento este del muro se reconoce un enlucido de color crema. 
En la sección inferior del muro se reconocen restos de azulejos y restos de calicanto, que forman parte de las improntas de los mismos azulejos y se distribuyen en todo el paramento. Debajo de estas improntas se registran algunos fragmentos de cerámica parte del revestimiento del paramento, previo a la colocación de azulejos.

Muro 08: Se encuentra ubicado en la Trinchera D, en el lado oeste de la unidad 03. Es una Estructura de planta rectangular, que se orienta de SO-NE. Tiene $1.78 \mathrm{~m}$ de largo, un ancho de $0.62 \mathrm{~m}$ y una altura promedio de $1.80 \mathrm{~m}$, funciona como muro perimétrico ya que forma parte de un recinto de planta cuadrangular que se ubicó debajo del altar mayor de la "capilla primitiva" de la Soledad. Se asienta sobre un piso de azulejos y ladrillo pastelero, y sobre este muro se construyó una plataforma de ladrillos donde se asienta el Muro 09 y el Arco 01.

El muro esta hecho de ladrillos unidos con mortero de calicanto, el paramento oeste del muro tiene enlucido de color crema y en la sección inferior, se reconocen restos de azulejos y restos de calicanto.

Muro 09: Se encuentra ubicado en la Trinchera D, en el lado sur de la unidad 03. Es una estructura de planta rectangular, que se orienta NO-SE. Tiene $0.76 \mathrm{~m}$ de largo, un ancho de $0.14 \mathrm{~m}$ y una altura promedio de $0.63 \mathrm{~m}$. Se asienta sobre el dintel del Vano de Acceso 02 y hacia el lado este se la adosa el Muro. Está hecho de ladrillos unidos con mortero de calicanto, y en el paramento sur del muro se reconoce un enlucido de color ocre.

Muro 10 (M10): Se encuentra ubicado en la Trinchera D, en el lado sur de la unidad 03. Es una estructura de planta rectangular, que se orienta de NE-SO. Tiene 0.49 $\mathrm{m}$ de largo, un ancho de $0.14 \mathrm{~m}$ y una altura promedio de $0.18 \mathrm{~m}$. Se asienta sobre el dintel del Vano de Acceso 02 y hacia el lado norte se adosa al Muro 09. Está hecho de ladrillos unidos con mortero de calicanto, y en el paramento oeste del muro se reconoce un enlucido de color ocre.

Muro 11: Se encuentra ubicado en la Trinchera D, en el lado sur de la unidad 03. Es una estructura de planta rectangular, que se orienta de SO-NE. Tiene $1.74 \mathrm{~m}$ de largo, un ancho de $0.37 \mathrm{~m}$ y una altura promedio de $1.79 \mathrm{~m}$, funciona como muro perimétrico ya que forma parte de un recinto de planta cuadrangular que se ubicó debajo del altar mayor de la "capilla primitiva" de la Soledad. Se adosa al Muro 06 y se asienta sobre un piso de azulejos y ladrillo pastelero, y sobre este muro se construyó una plataforma de ladrillos donde se asienta el dintel del Vano de Acceso 02. El muro esta hecho de ladrillos unidos con mortero de calicanto, el paramento oeste del muro, en la sección inferior presenta restos de azulejos y restos de calicanto.

Muro 12: Se encuentra ubicado en la Trinchera D, en el lado norte de la unidad 24 y el lado sur de la unidad 01. Es una estructura de planta rectangular, que se orienta de NO-SE. Tiene $0.90 \mathrm{~m}$ de largo, un ancho de $0.15 \mathrm{~m}$ y una altura promedio de 
$0.92 \mathrm{~m}$. Se asienta sobre una plataforma de ladrillos ubicada sobre el Muro $07 \mathrm{y}$ en el paramento norte se apoya el Arco 01. El muro esta hecho de ladrillos unidos con mortero de calicanto y tiene enlucido de color crema.

Estructura 01: Se encuentra ubicado en la Trinchera A, en el lado norte de la unidad 06. Es una estructura de planta rectangular, que se orienta de NO-SE. Tiene 1.31 $\mathrm{m}$ de largo, un ancho de $0.73 \mathrm{~m}$ y una altura promedio de $0.77 \mathrm{~m}$. Hacia el lado sur se asienta sobre el Muro 03 mientras que al lado norte se apoya al actual frontis de la Iglesia de Nuestra Señora de la Soledad. Está hecho de ladrillos unidos con calicanto, dispuestos a modo de soga-tizón y tienen un tamaño promedio de 0.30 de largo, $0.14 \mathrm{~m}$ de ancho y $0.06 \mathrm{~m}$ de espesor. Esta estructura funciona como cimiento de la columna de la actual Iglesia de la Soledad.

Estructura 02: Se encuentra ubicado en la Trinchera A, hacia el lado norte de las unidades 06, 07, 08 y 09. Es una estructura de planta rectangular, que se orienta de NO-SE. Tiene $5.30 \mathrm{~m}$ de largo, un ancho de $0.46 \mathrm{~m}$ y una altura máxima de $0.60 \mathrm{~m}$. Está construido con 4 hileras de adobes unidos sin argamasa, formando un encofrado que contenía a un vaciado de cantos rodados y calicanto (Estructura 04). Estos adobes miden $0.50 \mathrm{~m}$ de largo, $0.22 \mathrm{~m}$ de ancho y $0.12 \mathrm{~m}$ de espesor.

Estructura 03: Se encuentra ubicado en la Trinchera A, hacia el lado noroeste de las unidades $09^{\prime}, 10^{\prime}$ y $11^{\prime}$. Es una estructura de planta rectangular, que se orienta de SO-NE. Tiene $1.76 \mathrm{~m}$ de largo, un ancho de $0.33 \mathrm{~m}$ y una altura máxima de $0.42 \mathrm{~m}$. Está construido con 3 hileras de adobes unidos sin argamasa, formando un encofrado que contenía a un vaciado de cantos rodados y calicanto (Estructura 04). Estos adobes miden $0.51 \mathrm{~m}$ de largo, $0.21 \mathrm{~m}$ de ancho y $0.14 \mathrm{~m}$ de espesor.

Estructura 04: Se encuentra ubicado en la Trinchera A, en el lado norte de la unidad 08' y lado sur de la unidad 09'. Estructura de planta rectangular, que se orienta de NO-SE. Tiene $2.14 \mathrm{~m}$ de largo, un ancho de $0.29 \mathrm{~m}$ y una altura promedio de 0.22 $\mathrm{m}$. Está hecho de cantos rodados de $0.26 \mathrm{~m}$ de largo, $0.22 \mathrm{~m}$ de ancho y $0.15 \mathrm{~m}$ de espesor, los que están distribuidos ordenadamente y unidas con mortero de calicanto Esta estructura forma parte de la base del frontis de la actual Iglesia de la Soledad.

Estructura 05: Se encuentra ubicado en la Trinchera A, en el lado oeste de la unidad 09'. Es una estructura de planta rectangular, que se orienta de SO-NE. Tiene $1.50 \mathrm{~m}$ de largo, un ancho de $0.68 \mathrm{~m}$ y una altura promedio de $0.26 \mathrm{~m}$. Está hecho de cantos rodados de $0.26 \mathrm{~m}$ de largo, $0.12 \mathrm{~m}$ de ancho y $0.07 \mathrm{~m}$ de espesor, los que están distribuidos ordenadamente y unidas con mortero de calicanto. Esta estructura forma parte de la base del frontis de la actual Iglesia de la Soledad.

Estructura 06: Se encuentra ubicado en la Trinchera D, en la unidad 01. Es una estructura de planta rectangular, probablemente un nicho o altar, que se orienta de SO-NE. Tiene $0.90 \mathrm{~m}$ de largo, un ancho de $0.62 \mathrm{~m}$ y una altura promedio de $0.98 \mathrm{~m}$. Se 
asienta sobre un piso de azulejos y ladrillo pastelero, y hacia el lado sur se apoya en el Muro 07 (M07), formando la base del Arco 02. La estructura se proyecta hacia el lado norte, pero fue cortada por un muro de adobes. Está hecha de ladrillos unidos con mortero de calicanto, y en ambos paramentos se reconocen restos de calicanto, que forman parte de las improntas de azulejos que estuvieron recubriendo la estructura.

Estructura 07: se encuentra ubicado en la Trinchera A, hacia el lado noroeste de la unidad 01'. Es una estructura de planta rectangular, que se orienta de SO-NE. Tiene $1.40 \mathrm{~m}$ de largo y una altura máxima de $1.78 \mathrm{~m}$. Está construido con 12 hileras de adobes unidos sin argamasa, superpuestos con amarre simple, formando un encofrado que contenía a un vaciado de calicanto y cantos rodados. Estos adobes miden $0.50 \mathrm{~m}$ de largo y $0.14 \mathrm{~m}$ de espesor.

Arco 01: se encuentra ubicado en la Trinchera D, en el norte de las unidades 01, 02 y 03. Es una estructura de planta rectangular, que se orienta de NO-SE. Solo se conserva ciertas secciones de la estructura (en ambos lados, se conserva solo el riñón del arco), pero se puede inferir un largo promedio de $4.15 \mathrm{~m}$, un ancho máximo de $1.00 \mathrm{~m}$ y una altura promedio de $0.60 \mathrm{~m}$, funciona como arco de medio punto que se asienta en el Muro 07 por el lado oeste y Muro 08 por el lado este. Esta estructura fue hecha de ladrillo pastelero de $0.26 \mathrm{~m}$ de largo, $0.15 \mathrm{~m}$ de ancho y $0.06 \mathrm{~m}$ de espesor, unidos con calicanto, no se puede determinar una técnica de amarre ya que la estructura estaba cubierta con una capa de $0.005 \mathrm{~m}$ de enlucido de color crema. Hacia el lado norte la estructura se apoya en el Arco 02, por lo que se infiere que fue construida en un segundo momento de modificación de este espacio.

Arco 02: se encuentra ubicado en la Trinchera D, en el sur de la unidad 01'. Es una estructura de planta rectangular, que se orienta SO-NE. Solo se conserva parte del riñón del arco, y se registra un promedio de $0.90 \mathrm{~m}$ de largo, un ancho máximo de $1.26 \mathrm{~m}$ y una altura promedio de $1.63 \mathrm{~m}$, funciona como arco de medio punto que se asienta en el nicho o altar (estructura 06). Fue hecha con ladrillos de $0.29 \mathrm{~m}$ de largo, $0.15 \mathrm{~m}$ de ancho y $0.06 \mathrm{~m}$ de espesor los que estaban unidos con calicanto, no se puede determinar una técnica de amarre ya que la estructura esta derruida y lo que se conserva está cubierto con una capa enlucida de color crema. Hacia el lado sur se le apoya el Arco 01, y hacia el norte la estructura fue cortada por el basamento del actual frontis de la Iglesia de la Soledad.

Arco 03: se encuentra ubicado en la trinchera A, en el lado norte de las unidades 09', 10' y 11". Es una Estructura de planta rectangular, que se orienta de NO-SE. Tiene $3.70 \mathrm{~m}$ de largo, un ancho de $0.65 \mathrm{~m}$ y una altura promedio de $2.605 \mathrm{~m}$, funciona como arco de descarga ya que está asentado en la base de la bóveda sepulcral debajo de la actual Iglesia de Nuestra Señora de la Soledad.

El elemento arquitectónico base de esta construcción es el ladrillo pastelero unido con mortero de calicanto, y según la sección del arco, presenta distintos tipos de 
amarre: en la clave presenta amarre de soga - tizón, tizón, soga, en las dovelas presenta amarre de soga-soga, tizón-soga-tizón, soga-soga y en las columnas donde se asienta el arco, el amarre es de soga-tizón, soga-soga, soga-tizón. La línea de imposta tiene 4 ladrillos dispuestos a modo de tizón. Estos ladrillos miden aproximadamente $0.33 \mathrm{~m}$ de largo, $0.16 \mathrm{~m}$ de ancho y $0.06 \mathrm{~m}$ de espesor. Es importante detallar que la luz y flecha del arco de descarga estaban selladas con ladrillos de las mismas dimensiones y del mismo tipo de mortero.

Piso empedrado: superficie de uso, reconocida en todas las trincheras de excavación, orientado NO-SE. En la trinchera A, el piso está construido con cantos rodados de pequeño tamaño (entre $0.08 \mathrm{~m}$ y $0.20 \mathrm{~m}$ ) dispuestos ordenadamente formando figuras fitomorfas y separadas cada $0.90 \mathrm{~m}$, por líneas verticales ordenadas a modo de espiga, entre cada franja de diseños. En la sección oeste de la trinchera el piso empedrado cambia de diseño y pasa a ordenarse de manera horizontal, formando franjas separadas cada $0.80 \mathrm{~m}$ y formando una suerte de "botones" independientes, con piedras más pequeñas (0.04 y $0.07 \mathrm{~m}$ ). Estos guijarros eran colocados a junta seca y se caracterizaban por tener dimensiones y tonalidades de colores similares (verde jade, celeste, aguamarina oscura). Fue reconocido en las unidades 52, 53, 54, $55,56,75,76,77$ y 78 . Hacia la unidad 54 se puede identificar la base del muro 01 que se asienta sobre el piso empedrado y hacia el lado norte del piso, en las unidades 29,30 y 31 se registra el umbral de un vano de acceso delimitado por un peldaño y dos quicios que intruyeron en este espacio. En las unidades 29 y 52 no se ha logrado conservar este piso empedrado, ya que el terreno ha sido bastante removido por las diferentes construcciones de épocas contemporáneas. Este piso se reconoce a una profundidad de 0.70 y $0.85 \mathrm{~m}$.

En la trinchera D, el piso empedrado en esta sección registrado a una profundidad de $1.15 \mathrm{~m}$ también fue construido con cantos rodados (entre $0.10 \mathrm{~m}$ y $0.13 \mathrm{~m}$ ) y fueron dispuestos ordenadamente, separadas por líneas horizontales entre cada diseño. Este piso fue reconocido en las unidades 47 y 48 , y hacia la sección norte se registra el Muro 03 y Muro 04, cuyas bases se asientan sobre el piso empedrado. De igual forma, en esta sección se registró el hoyo depósito de deshechos diversos.

En ambas trincheras (A y D), el piso empedrado fue construido sobre un apisonado de tierra suelta, de color marrón, y limpia, sin ningún tipo de inclusiones. Este apisonado era compactado y sobre este se formaban los diseños. En el caso de la Trinchera A, debajo de este apisonado se colocó un gran relleno de cantos rodados de gran tamaño y tierra mezclada con material cultural y piedras pequeñas, que acondicionó el terreno estéril para poder construir el empedrado y las estructuras circundantes.

Piso de ladrillos: se encuentra ubicado en la trinchera A, en el lado norte de las unidades 30, 31, 32 y 33. Se orienta de NO-SE. Tiene $8.10 \mathrm{~m}$ de largo, un ancho de $0.45 \mathrm{~m}$ y un espesor de $0.05 \mathrm{~m}$. El piso fue construido con ladrillo pastelero de pe- 
queñas dimensiones ( $0.14 \mathrm{~m}$ de largo, $0.20 \mathrm{~m}$ de ancho y $0.04 \mathrm{~m}$ de espesor) unido con cal y arena fina, dispuesto en forma de "espina de pescado" y en otras secciones a manera de "soga".

Estos ladrillos fueron colocados sobre una superficie de cal y barro compactado que cubrió este espacio. En la trinchera A solo se conservan remanentes del piso pastelero ya que la mayor parte ha sido destruida con la intervención de construcciones actuales.

Piso de azulejos: superficie de uso, reconocida en la Trinchera D, unidades 01,01',02,02',03,03'. Hacia el norte, está delimitado por el actual frontis de la Iglesia de la Soledad, hacia el sur por el muro 06, hacia el este con el Muro 07 y hacia el oeste con los muros M08, M11 y el vano de Acceso 02. Tiene una extensión promedio de $4.165 \mathrm{~m}$ (NO-SE) y $3.045 \mathrm{~m}$ (SO-NE) y se registró a $2.94 \mathrm{~m}$ del piso actual de la Plazuela de San Francisco.

El piso está conformado por azulejos de $0.13 \mathrm{~m}$ de largo y $0.13 \mathrm{~m}$ de ancho y ladrillo pastelero pequeño ( $0.27 \mathrm{~m}$ de largo y $0.14 \mathrm{~m}$ de ancho). Los azulejos tienen diseños florales y algunos fueron ordenados cada 4, formando bloques de diseños más grandes ( $0.26 \mathrm{~m}$ de largo y $0.26 \mathrm{~m}$ de ancho), alternando con un ladrillo entre bloque y bloque y tres líneas de listelos azul y blanco, que probablemente rodeo todo el recinto. Este piso fue asentado con un mortero de cal y tierra suelta, sobre un falso piso de calicanto.

Vano de acceso 01: elemento arquitectónico ubicado en la Trinchera A, en las unidades 29, 30 y 31, hacia el lado norte del piso empedrado. Tiene una longitud promedio de $3.78 \mathrm{~m}$ de largo y $0.78 \mathrm{~m}$ de ancho. Está delimitado por dos quicios, hechos uno a cada extremo del vano, un umbral hecho de adoquines de calicanto y un peldaño hecho de ladrillo pastelero. Este acceso sirvió como flujo de circulación entre el piso empedrado de la plazuela y la antigua Iglesia de la Soledad.

Vano de acceso 02: elemento arquitectónico ubicado en la trinchera D, en la unidad 3, hacia el lado este del piso de azulejos. Tiene $0.87 \mathrm{~m}$ de ancho y $1.82 \mathrm{~m}$ de alto. Está delimitado por dos muros "dos jambas", dos muros y un dintel hecho de ladrillos de $0.06 \mathrm{~m}$ de espesor. Este acceso probablemente sirvió como flujo de circulación entre el recinto decorado con azulejos y la bóveda sepulcral reconocida en la Trinchera A. El vano está sellado con tierra suelta mezclada con restos de ladrillos, cantos rodados y restos de material cultural, similar al registrado en el relleno de la capa 01 de las unidades 01,01 ', 02, 02 ', 03.

Quicio 01: ubicado en la Trinchera A, en la unidad 31, hacia el lado noreste del piso empedrado. Tiene $0.68 \mathrm{~m}$ de largo, $0.61 \mathrm{~m}$ de ancho y $0.31 \mathrm{~m}$ de profundidad. Es de planta circular y se ubica hacia el lado este del Vano de Acceso 01, e intruye en el Peldaño 01. Está construido con ladrillo y calicanto, y funciono como parte de la puerta de ingreso a la antigua Iglesia de la Soledad. 
Quicio 02 : Ubicado en la Trinchera A, en la unidad 29 y 30, hacia el lado noroeste del piso empedrado. Tiene $0.50 \mathrm{~m}$ de largo, $0.58 \mathrm{~m}$ de ancho y $0.52 \mathrm{~m}$ de profundidad. Es de planta circular y se ubica hacia el lado oeste del Vano de Acceso 01, e intruye en el Peldaño 01. Está construido con ladrillo y calicanto, y funciono como parte de la puerta de ingreso a la antigua Iglesia de la Soledad.

Peldaño 01: ubicado en la Trinchera A, en las unidades 29, 30 y 31, hacia el lado norte del vano de acceso $01 \mathrm{y}$ del piso empedrado. Tiene $5.14 \mathrm{~m}$ de largo, $0.57 \mathrm{~m}$ de ancho y $0.16 \mathrm{~m}$ de altura. Es de planta rectangular y hacia los extremos tiene forma triangular. Está hecho con ladrillo de $0.27 \mathrm{~m}$ de largo, $0.14 \mathrm{~m}$ de ancho y $0.04 \mathrm{~m}$ de espesor, unido con mortero de calicanto y colocado a modo de soga, en pila lateral. Fue construido sobre el piso pastelero y los quicios 01 y 02 han intruido en esta estructura y funciono como parte del acceso principal a la antigua Iglesia de la Soledad.

Peldaño 02: Ubicado en la Trinchera A, en la unidad 33, hacia el lado norte del muro 02. Tiene $1.40 \mathrm{~m}$ de largo, $0.30 \mathrm{~m}$ de ancho y $0.08 \mathrm{~m}$ de altura. Es de planta rectangular y hacia los extremos tiene forma triangular. Está construido con ladrillo unido con mortero de calicanto y colocado a modo de soga. Fue construido sobre el piso pastelero funciono como parte de la estructura interna de la antigua Iglesia de la Soledad.

Umbral 01: ubicado en la Trinchera A, en las unidades 30 y 31, hacia el lado norte del piso empedrado y orientado de Noreste a Suroeste. Tiene $2.70 \mathrm{~m}$ de largo y 0.27 $\mathrm{m}$ de ancho, está conformado por 11 adoquines o bloques de calicanto, de diferentes dimensiones, pero un espesor regular de $0.16 \mathrm{~m}$ y de los cuales $0.08 \mathrm{~m}$ se apoyaron sobre el piso pastelero y peldaño 01. Es de planta rectangular y fue construido sobre el relleno colocado para formar el piso empedrado (ver la cala 1 de la capa 4).

Ventanal 01: elemento arquitectónico cuya finalidad primordial es servir de flujo de comunicación entre un espacio interior y el exterior, proveer iluminación y ventilación natural. Este ventanal se ubica en la Trinchera D, en las unidades 24 y 01 y está orientado oeste-este. Posee planta rectangular, con un largo promedio de 1.15 $\mathrm{m}$ de largo, $0.89 \mathrm{~m}$ de ancho y una altura de $1.02 \mathrm{~m}$. Está hecho de ladrillos unidos con mortero de calicanto, con una superficie achaflanada y se conservan restos de enlucido beige, de $0.05 \mathrm{~m}$ de espesor.

Dintel 01: ubicado en la Trinchera D, en la unidad 03, en la parte superior del vano de acceso 02 , hacia el lado este del piso de azulejos y orientado de NE-SO, tiene 0.84 $\mathrm{m}$ de largo, $0.68 \mathrm{~m}$ de ancho y una altura promedio de $0.35 \mathrm{~m}$. Está hecho de ladrillo de $0.30 \mathrm{~m}$ de largo, $0.15 \mathrm{~m}$ de ancho y $0.06 \mathrm{~m}$ de espesor, asentado con mortero de calicanto y dispuestos a modo de soga-tizón, se apoya en los muros M08 y M11, debajo de los muros M09 y M10.

Jamba 01: elemento arquitectónico ubicado en la Trinchera D, en la unidad 03, en el paramento lateral interno del Vano de Acceso 02, hacia el lado derecho del mismo. No es posible definir las dimensiones totales, ya que se excavó solo parte 
del acceso, pero se logra registrar un largo promedio de $0.29 \mathrm{~m}$, un ancho de 0.08 $\mathrm{m}$ y una altura de $1.80 \mathrm{~m}$. Está hecha de ladrillo asentado con mortero de calicanto, colocado a modo de tizón.

Jamba 02: elemento arquitectónico ubicado en la Trinchera D, en la unidad 03, en el paramento lateral interno del vano de Acceso 02, hacia el lado izquierdo del mismo. No es posible definir las dimensiones totales, ya que se excavo solo parte del acceso, pero se logra registrar un ancho de $0.075 \mathrm{~m}$ y una altura de $1.73 \mathrm{~m}$. Está hecha de ladrillo de ancho y $0.05 \mathrm{~m}$ de espesor, que fue asentado con mortero de calicanto y colocado a modo de tizón.

Hoyo 1: este elemento arquitectónico fue registrado en la Trinchera D, hacia el lado norte de las unidades 47 y 48 e intruye en el piso empedrado, por debajo de las bases de los muros M04 y M05. Está delimitado por cantos rodados colocados a junta seca, tiene aproximadamente $1.05 \mathrm{~m}$ de largo (oeste-este), $0.66 \mathrm{~m}$ de ancho (norte-sur) y $1.01 \mathrm{~m}$ de profundidad. De acuerdo con las evidencias recuperadas, podría corresponder a un depósito de desechos.

\section{RESULTADOS DE LOS ANÁLISIS DE CONSERVACIÓN}

Los estudios fisicoquímicos de un conjunto de muestras procedentes de las excavaciones arqueológicas nos permitieron conocer el índice del potencial hidrógeno $(\mathrm{pH})$, la conductividad eléctrica y los diversos tipos de sales solubles presentes en cada muestra recogida, y si estas variaciones influencian de alguna manera en su actual estado de conservación. Se desarrollaron análisis de amplitud de imagen para conocer a nivel macro las alteraciones y las características físicas que no son discernibles a simple vista. Esta información se adjuntó en fichas técnicas con el fin de mantener un orden, así como una mejor lectura de la información y con un interés evidente para los estudios previos a las actuaciones de su conservación.

Los resultados identificados en los análisis fisicoquímicos mostraron ligeras variaciones en los índices de $\mathrm{pH}$ y conductividad eléctrica. De esta manera se permite apreciar la irregular distribución de las concentraciones salinas.

Las sales predominantes en el suelo se pueden encontrar en forma de cloruros (Cl-), sulfatos ( $\mathrm{SO} 4)$, carbonatos ( $\mathrm{CO} 3$ ) lo cual pueden causar variaciones en las características del mortero según la concentración en la que se presenten.

La presencia de estas sales solubles ha sido en menor grado, pero pueden producir un deterioro a largo plazo y más aún si los nuevos hallazgos arqueológicos estarán expuestos a la intemperie. Con esto se puede inferir, que la presencia de sales ayudaría de alguna manera al desarrollo de las afectaciones como descamación, exfoliación, disgregación o descohesión de los diversos estratos.

Las sales más frecuentes identificadas en las muestras corresponden a los cloruros, seguido por los sulfatos. Esto sería muy perjudicial específicamente en la pin- 


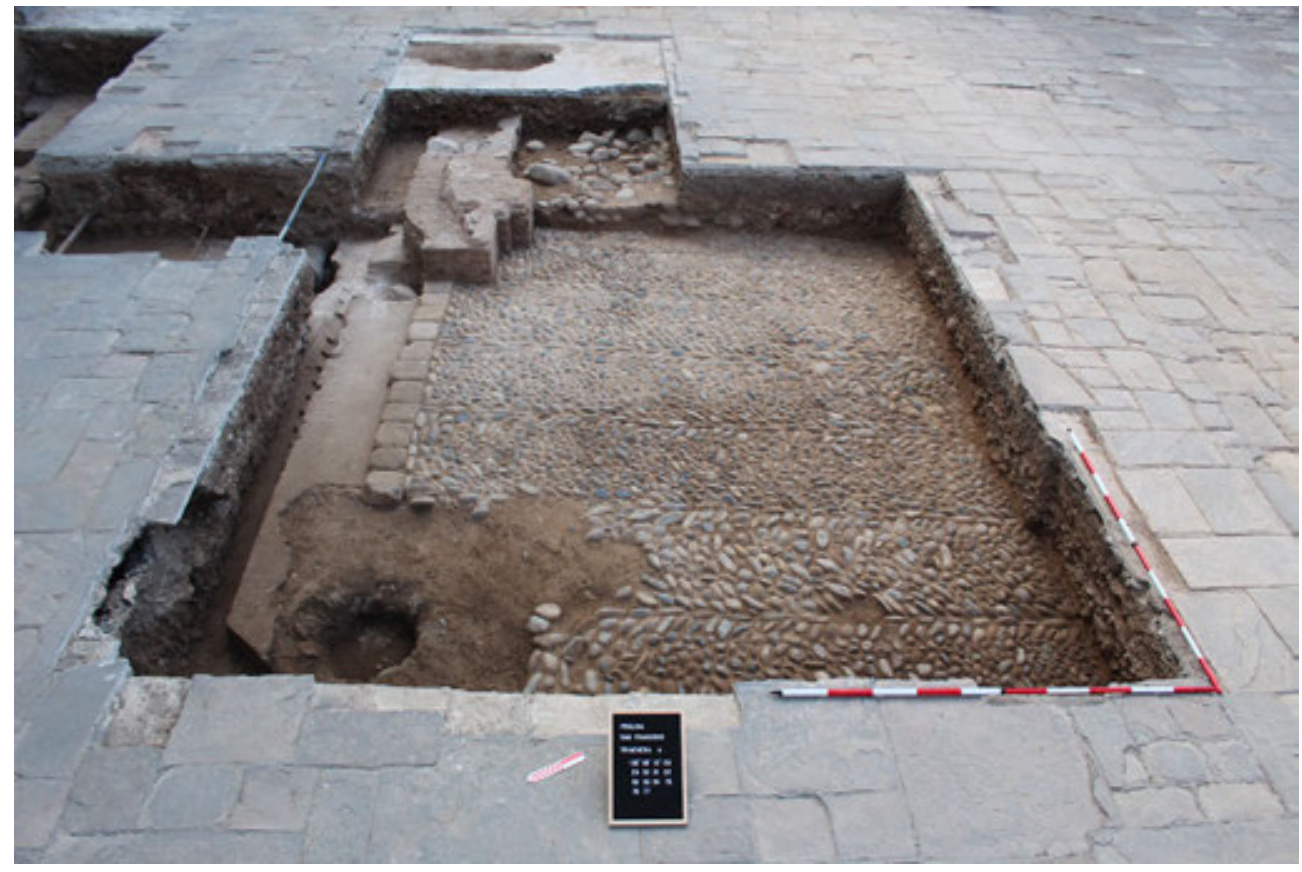

Figura 13. Vista de la Trinchera A con sus elementos arquitectónicos.

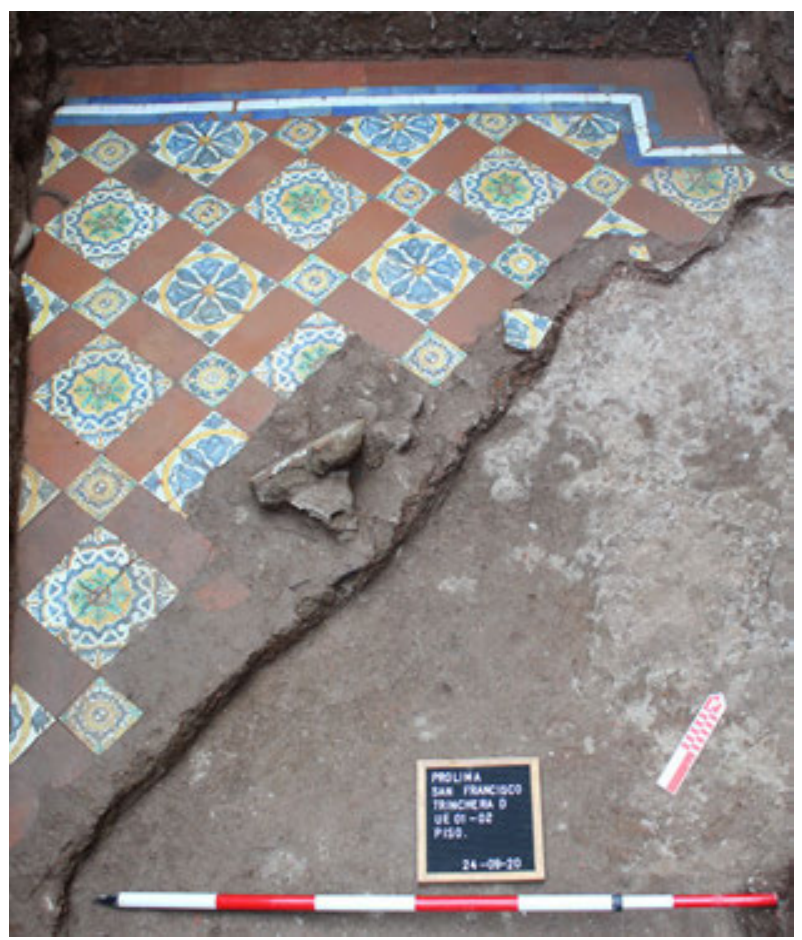

Figura 14. Vista del piso de azulejos. 

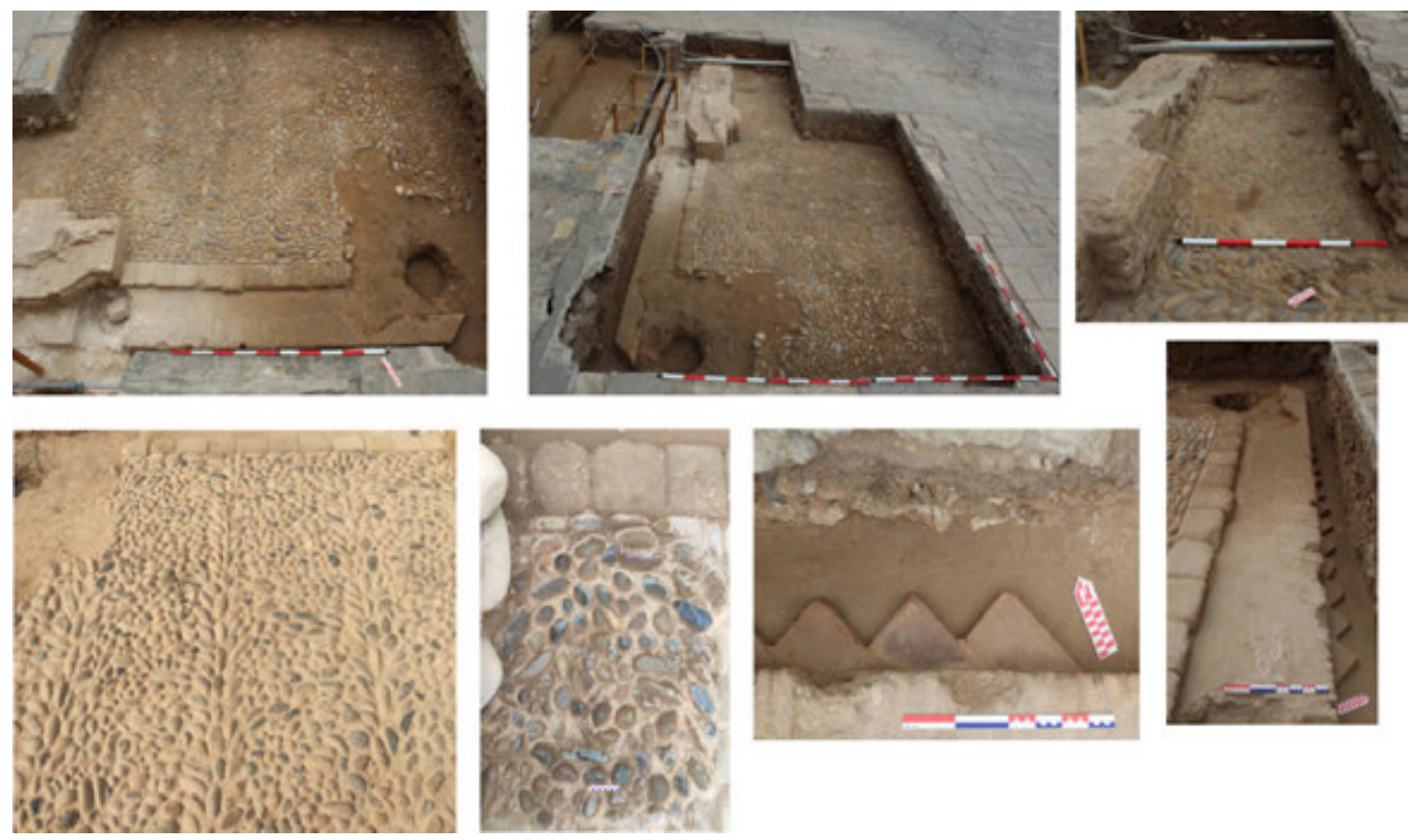

Figura 15. Características arquitectónicas del piso empedrado.
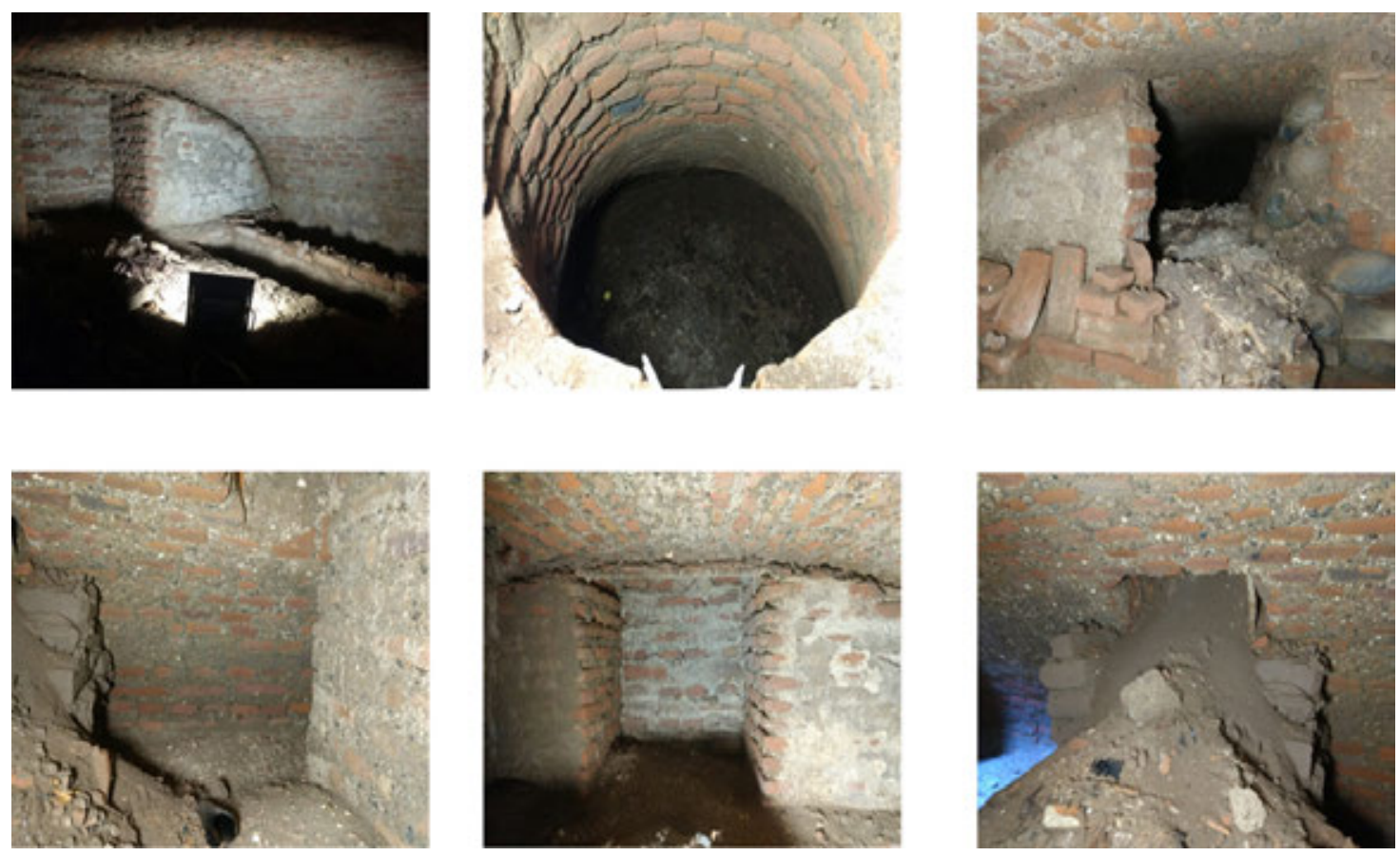

Figura 16. Características arquitectónicas de la bóveda sepulcral. 

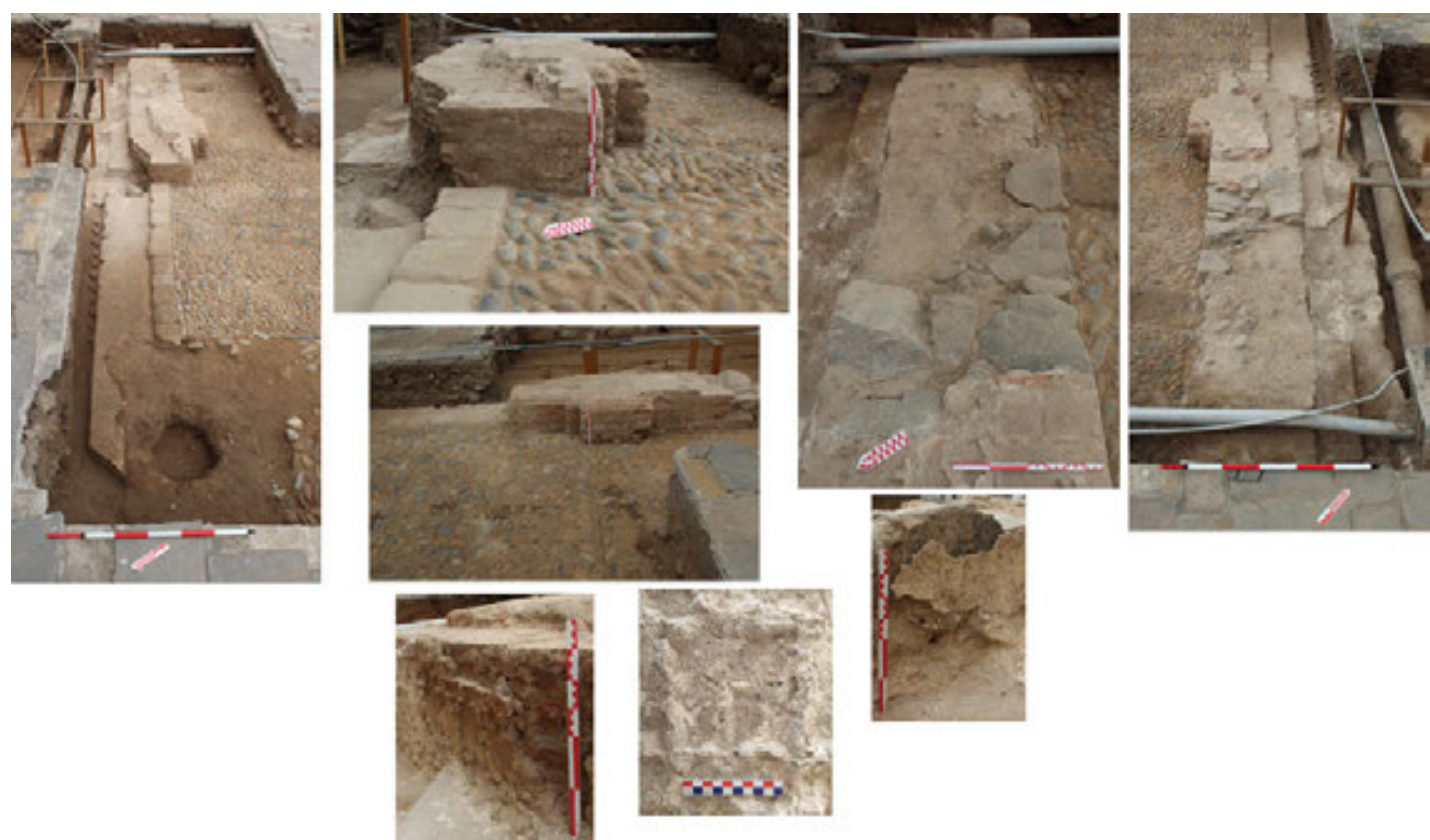

Figura 17. Características arquitectónicas de los elementos murarios.

tura mural de tonalidad rojiza donde evidenció una ligera presencia de estas sales solubles que afectan la superficie de la capa pictórica. Se complementó esta información con los análisis de amplitud de imagen por el cual se pudo observar la disgregación del material y en algunas zonas la descohesión de los estratos, donde la capa pictórica ha perdido su propiedad de adhesión con el enlucido, dejando ligeras oquedades y formando pequeñas fisuras.

Los azulejos son otro tipo de material que se han visto afectados por la mayor concentración de cloruros en su superficie, y esto probablemente se debe a que han estado ocultos bajo tierra durante muchos años y al estar en contacto con los morteros de relleno, más la filtración de la humedad producto de una tubería que se encuentra a una corta distancia ha propiciado el desarrollo de estas afectaciones. Es por esta razón que para los tratamientos de conservación de azulejos se deberá tener en cuenta la remoción de estas sales solubles mediante una limpieza con materiales neutros y no agresivos.

Los índices de conductividad eléctrica más altos corresponden al piso o calzadura de canto rodado (M-019) y el enlucido presente en el muro pretil de la UE-33 (M-002). La presencia de estos iones está relacionada a que mayor conductividad eléctrica, mayor concentración de cloruros. Son muy solubles e higroscópicas y la forma de alteración más predominante es su pulverización o disgregación que en los enlucidos puede ser muy perjudicial si no se elimina y se consolida. 
Como conclusión metodológica de este trabajo, se considera que es muy importante realizar este tipo de análisis físico-químicos para determinar la presencia de sales en diversos materiales presentes en los hallazgos arqueológicos de la Plazuela de San Francisco de Lima. Además, constituye a estudios analíticos complementarios que ayudarán de alguna manera en el diagnóstico de su estado de conservación. De ello se podrán derivar las recomendaciones de actuación para llevar a cabo la limpieza y los demás procesos de conservación y restauración, evitando la progresión por repetición del mecanismo en el desarrollo de las sales (Tabla 1).

Tabla 1. Muestras identificadas para la identificación de pH, conductividad eléctrica y sales.

\begin{tabular}{|l|l|l|l|l|l|l|}
\hline MUESTRA & \multicolumn{1}{|c|}{ UBICACIÓN } & pH & CE & \multicolumn{1}{|c|}{$\mathbf{C O}_{3}^{-2}$} & $\mathbf{C l}^{-}$ & SO $_{4}^{-2}$ \\
\hline M-001 & Muro pretil UE-33 & 7.01 & 0.32 & - & \pm & - \\
\hline M-002 & Muro pretil-enlucido UE-33 & 6.87 & 1.4 & - & ++ & - \\
\hline M-003 & Estrato negruzco UE-11 & 6.51 & 0.5 & - & ++ & \pm \\
\hline M-004 & Muro pretil-impronta UE-33 & 6.80 & 0.34 & - & + & - \\
\hline M-005 & Corrosión tubería eléctrica & 6.31 & 0.31 & - & \pm & - \\
\hline M-006 & Enlucido UE-01 & 6.43 & 0.27 & - & + & - \\
\hline M-007 & Revoque de la impronta azulejo & 6.57 & 0.29 & - & + & - \\
\hline M-008 & Revoque azulejos & 7.04 & 0.30 & - & + & - \\
\hline M-009 & Azulejo & 6.90 & 0.19 & - & ++ & - \\
\hline M-010 & Revoque azulejo UE-01 & 8.49 & 0.56 & - & + & \pm \\
\hline M-011 & Enlucido UE-01 & 7.86 & 0.30 & - & + & \pm \\
\hline M-012 & Piso azulejos UE-01 & 7.31 & 0.21 & - & \pm & - \\
\hline M-013 & Corrosión Tubo de metal & 7.55 & 0.31 & - & - & ++ \\
\hline M-014 & Biodeterioro muro UE-24 & 6.85 & 0.24 & - & \pm & - \\
\hline M-015 & Pintura mural UE-03 & 7.31 & 0.23 & - & + & \pm \\
\hline M-016 & Mortero de cal (base pórtico) & 7.00 & 0.48 & - & \pm & \pm \\
\hline M-017 & Ladrillo & 7.34 & 0.94 & - & \pm & \pm \\
\hline M-018 & Estrato & 6.99 & 0.20 & - & + & - \\
\hline M-019 & Piso calzadura & 7.08 & 1.66 & \pm & ++ & \pm \\
\hline M-020 & Base cimentación cal & 7.36 & 0.24 & - & \pm & - \\
\hline M-021 & Enlucido UE-33 & 7.48 & 0.31 & - & \pm & - \\
\hline
\end{tabular}




\section{CONCLUSIONES}

El registro arqueológico del palimpsesto de la plazuela de San Francisco permitió obtener varias evidencias, desde las jardineras de la plazuela con planta radial (fines siglo XIX e inicios del siglo XX) hasta las diversas obras de saneamiento y de electricidad, desde mediados del siglo XIX hasta finales del siglo XX.

Se han identificado restos de piso empedrado en todas las áreas de excavación en la plazuela San Francisco que corresponden a un mismo periodo (siglo XVII-XIX aproximadamente). No se ha registrado evidencias de un piso o nivel de piso más temprano que el del piso empedrado, por lo que se puede asumir que es el mismo nivel de ocupación desde tiempos fundacionales de la plazuela.

Los restos de las bases de muros frontales pertenecen a una fundación inicial de la "capilla primitiva" de Nuestra Señora de la Soledad en 1603. Las bases de este muero de ladrillo y piedra, que se extiende de oeste a este ocupan el mismo espacio que el posterior muro pretil de finales del siglo XVII, por lo que sirvieron de bases para esa construcción. Este muro separaba la plazuela de San Francisco del conjunto Franciscano hasta finales del siglo XIX cuando fue demolido.

Destaca el descubrimiento de un sistema de bóvedas, arcos y criptas que están asociadas a la "capilla primitiva" de Nuestra Señora de la Soledad, la misma que se extiende por debajo de la actual plazuela. Se pudo identificar la capilla subterránea ubicada originalmente bajo el altar mayor de la "capilla primitiva" de la Soledad, que incluye gran parte del piso original de azulejos, el posible santo sepulcro del Cristo yacente y un acceso sellado a la cripta sepulcral. Por las características deposicionales, el sello de la capilla subterránea tuvo un tratamiento organizado de carácter ritual.

La evidencia material nos muestra dos momentos en el uso de la actual plazuela de San Francisco entre los siglos XVII y XVIII: un primer momento corresponde a la "capilla primitiva" de Nuestra Señora de la Soledad cuya construcción fue culminada hacia el año 1603 y cuyos restos, específicamente del frontis y el acceso principal, han sido encontrados en nuestra investigación; El segundo momento, que corresponde a la construcción de la nueva Capilla de Nuestra Señora de la Soledad en 1675, nos da a conocer que las bases del frontis de la antigua capilla fueron "reutilizadas", con el fin de construir un muro "pretil".

La arqueología histórica en la plazuela de San Francisco tuvo como reto registrar los ciclos históricos de corta y mediana duración, expresados en la cultura material, teniendo como propuesta contrastar el registro histórico y aportar nuevas evidencias sobre los usos, costumbres y mentalidades de la sociedad colonial y republicana para dejar como aporte el que sus resultados sean una herramienta fundamental para reconfigurar el paisaje urbano en el CHL. 
Agradecimientos: A Luis Martín Bogdanovich y Héctor Walde, funcionarios de PROLIMA. A Lea Rojas por su apoyo tanto en la residencia de campo como en las labores de registro y su ética profesional durante el desarrollo del proyecto. A Lady Osorio por los análisis de conservación requeridos por el director del proyecto, a Juan Aldave por sus oficios como arqueólogo de campo y ayudar a repensar las estrategias. A los colegas Miguel Enríquez y Diego Pariona por su participación diligente. A César Ponce, responsable de la aerofotogrametría y registros gráficos, a Lucía Silva por las valiosas fotografías al interior de la cripta sepulcral. A Toño Coello, Boris Marquéz, Elmer Zapata y Jose Menzala por sus consejos y apreciaciones en campo. A Marco Cumpa, Rudy Cochache, Alfredo Blas, Jorge Soto, Raúl Albitrez, William Horna, Daniel Martínez, Eduard Calvas porque sin su trabajo de campo y lealtad este proyecto no hubiera sido posible. Finalmente, al Hermano Soleano Rafael Andrade y a Fray Ernesto Chambi OFM, guardianes del Patrimonio Cultural Inmaterial de San Francisco.

\section{REFERENCIAS BIBLIOGRÁFICAS}

Agurto Calvo, S. (1984). Lima prehispánica. Municipalidad de Lima Metropolitana, Lima.

Alzate, A. (2011). La Arqueología Colonial como herramienta para contrastar la historia escrita. ArqueoWeb, 13.

Angrand, L. (1972). Imagen del Perú en el siglo XIX. Lima: Milla Batres.

AUTORIDAD NACIONAL DEL AGUA (ANA). (2016). Rímac: historia del río hablador. Ed. Lima. Lima.

Bernales Ballesteros, J. (1972). Lima, La Ciudad y sus Monumentos E.E.H.A.S. Sevilla.

Bromley, J. (2005). Las viejas calles de Lima. Municipalidad Metropolitana de Lima, Edilibros, Gerencia de Educación, Cultura y Deportes. Lima.

Bromley, J; Barbagelata, J. (1945). Evolución urbana de Lima. Talleres gráficos de la editorial Lumen, Lima.

Cobo, B. ([1639] 1964). Fundación de Lima Obras del P. Bernabé Cobo de la Compañía de Jesús. Biblioteca de Autores Españoles (continuación), vol. 92, p. 277-460. Ediciones Atlas, Madrid,

de Zárate, A. (1944). Historia del descubrimiento y conquista del Perú. Lib. e imp. D. Miranda, Madrid.

Dianich, S. (2013). La Iglesia y sus Iglesias. Entre teología y arquitectura. Lima: PUCP.

Durán Montero, M. (1994). Lima en el siglo XVII: arquitectura, urbanismo y vida cotidiana. Madrid. 
Eguiguren, L. (1945). Las calles de Lima. Lima: [s.n.]

FAUA UNI Fundación Ford. (1988). Inventario del Patrimonio Monumental Inmueble de Lima.

Gento Sanz, B. (1945). San Francisco de Lima. Estudio histórico y artístico. Lima.

Gunther Doering, J y Mitrani Reaño, H. (2013). Memorias de Lima. Tomo I. Empresa Editorial El Comercio. Lima.

Lee, B.T. et al. (1937). Libros de Cabildos de Lima. Impresores: Torres Aguirre, Lima.

Mattos-Cárdenas, L. (2012). Lima virreinal. Orígenes y desarrollo de una ciudad compleja. En Palmerio, G., Lombardi, A. y Montuori, P. (Eds.). Centro histórico. Conocimiento y restauración (pp.18-23). Gangemi Editore spa.

Middendorf, E. W. (1974). Perú: observaciones y estudios del país y sus habitantes durante una permanencia de 25 años. Universidad Nacional Mayor de San Marcos.

Morgado Maurtua, P. (2007). Un Palimpsesto Urbano: Del asiento Indígena de Lima a la Ciudad Española de Los Reyes. Universidad de Sevilla.

Pizarro, H. (2019). Proyecto de Investigación Arqueológica Plazuelas de Lima. Proyecto presentado al Ministerio de Cultura.

Pizarro, H. (2021). Proyecto de Investigación Arqueológica Plazuelas de Lima. Informe Final presentado al Ministerio de Cultura.

Osorio, A. (2008). Inventing Lima: Baroque Modernity in Peru's South Sea Metropolis. Springer, EEUU.

Ramón, G. (2005). La plaza, las plazas y las plazuelas: uso del espacio público en Lima. En Gutiérrez Arbulú, L (comp.). Lima en el siglo XVI, (pp 103-132). PUCP.

Renfrew, C. y Bahn, P. (1991). Arqueología: Teoría, Métodos y Práctica. London: Thames and Hudson.

San Cristóbal, A. (2013). Nueva visión de San Francisco de Lima. Instituto Francés de Estudios Andinos

Sáenz, I. (2007). Capítulo, 1. De la urbe fundacional a la ciudad de los borbones: Historiografía y periodificación del urbanismo virreinal limeño (1535-1824), (pp. 24-29). Lima. 


\section{SOBRE EL AUTOR}

\section{Harry Pizarro Anaya}

Es arqueólogo por la Universidad Nacional Mayor de San Marcos y con estudios de Maestría en Gestión del Patrimonio Cultural, con 25 años de experiencia en distintos campos de la arqueología peruana, tanto en el sector público como en el privado. Ha participado en los siguientes proyectos arqueológicos: Huacoy, Huallamarca, Pacopampa, Huaca Pucllana, Omo Alto, Huaycán de Cieneguilla, Iglesia de San Lázaro, Garagay, PIA Las Bambas entre otros. Ha sido especialista en Paisaje del CIIRC del Museo Nacional de Chavín y director del Proyecto Plazuelas de Lima. En arqueología histórica tiene una publicación: "Hermandades y cofradías en la Iglesia del Señor san LÁZARO, Lima. Siglos. XVI-XVIII: apuntes desde la arqueología colonial" (2017). 